\title{
Greenland surface mass balance simulated by a regional climate model and comparison with satellite derived data in 1990-1991.
}

\author{
Xavier Fettweis ${ }^{1}$, Hubert Gallée ${ }^{2}$, Filip Lefebre ${ }^{3}$, Jean-Pascal van Ypersele ${ }^{1}$
}

6

Abstract. The 1990 and 1991 ablation seasons over Greenland are simulated with a coupled atmosphere-snow regional climate model with a $25 \mathrm{~km}$ horizontal resolution. The simulated snow water content allows a direct comparison with the satellite derived melt signal. The model is forced with 6-hourly ERA-40 reanalysis at its boundaries. An evaluation of the simulated precipitation and a comparison of the modelled melt zone and the surface albedo with remote sensing observations are presented. Both the distribution and quantity of the simulated precipitation agree with observations from coastal weather stations, estimates from other models and the ERA-40 reanalysis. There are overestimations along the steep eastern coast which are most likely due to the "topographic barrier effect". The simulated extent and time evolution of the wet snow zone compare generally well with satellite derived data, except during rainfall events on the ice sheet and because of a bias in the passive microwave retrieved melt signal. Although satellite based surface albedo retrieval is only valid in the case of clear sky, the interpolation and the correction of these data enable us to validate the simulated albedo on the scale of the whole Greenland. These two comparisons highlight a large sensitivity of the remote sensing observations to weather conditions. Our high resolution climate model has been used to improve the retrieval algorithms by taking more fully into account the atmosphere variability. Finally the good agreement of the simulated melting surface with the improved satellite signal allows a detailed estimation of the melting volume from the simulation.

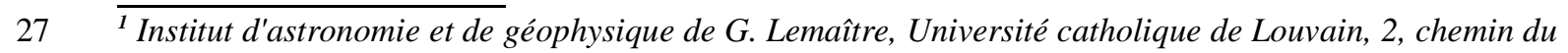
cyclotron, B-1348 Louvain-La-Neuve, Belgium.

${ }^{2}$ Laboratoire de Glaciologie et Géophysique de l'Environnement, CNRS, Grenoble, France.

$30{ }^{3}$ Vito-IMS (Flemish Institute for Technological Research - Integral Environmental Studies) Mol, Belgium. 


\section{Introduction}

[1] The 2001 Intergovernmental Panel on Climate Change (IPCC) report predicts heavier snowfalls in winter and an increase of the summer melt in Greenland as part of a projected global warming due to anthropogenic forcing (Houghton et al., 2001). Without quantifying it precisely, the IPCC predicts that the summer melt will dominate. A subsequent mass loss (due to ice melt and ice discharge) of the Greenland ice sheet will occur, with an impact on sea level and possibly on the Atlantic Ocean circulation. This motivates the increasing interest to understand and estimate how the Surface Mass Balance (SMB) and the ablation rate will respond to a climate change. It is generally believed that about half of the annual mass loss comes from snow/ice melting. The rest comes from ice discharge. According to Zwally et al. (2002), an increasing melt will increase the ice discharge. Indeed the melt water reaching the glacier bed lubricates the ice/bedrock interface, facilitating glacier sliding. This will also thin the margin and cause the ice sheet retreat from the coast as pointed out by Krabill et al. (1999).

[2] A number of issues make the modelling of Greenland climate a complicated task. Indeed models with high horizontal resolution are needed (i) to improve precipitation simulations (Christensen et al. (1998), Bromwich et al. (2001), Murphy et al.

51 (2002)) and (ii) to represent explicitly the ablation zone. The latter is not wider than 100 $\mathrm{km}$ in Greenland. Snow and ice melt modelling requires elaborate physics (Xue et al. (2003)). Cassano et al. (2001) mention that the use of a fixed albedo leads to large errors in the simulated net radiation budget over melting ice surfaces. Neglecting to take into account the night-time refreezing of retained meltwater overestimates melt (Pfeffer et al., 1991 ; Gallée and Duynkerke, 1997). Katabatic winds play an important role in the surface energy balance (Duynkerke and van den Broeke, 1994 ; van den Broeke et al., 1994). Consequently their modelling must be detailed. A Regional Climate Model 
(RCM) nested in a General Circulation Model (GCM) or observation-based reanalysis

(Giorgi and Mearns, 1999), answer some of these issues, i.e. higher spatial resolution (improved orography), more sophisticated atmospheric physics and surface parameterizations designed for polar regions. That is why the RCMs are more and more used to estimate the Greenland ice sheet mass balance (Hanna et al. (2002), Box and Rink (2003), Mote (2003), Box et al. (2004)).

[3] Remote sensing observations can be used to validate a model but a model can also improve satellite retrieval algorithms. We present in this paper an evaluation of a coupled atmosphere-snow RCM having an horizontal resolution of $25 \mathrm{~km}$ over Greenland. The model is referred to as MAR (Modèle Atmosphérique Régional) and is nested 69 into the ERA-40 reanalysis for the period including the 1990 and 1991 summers. These years are rich in measurement campaigns (ETH-Camp : Ohmura et al. (1992), GIMEX : Oerlemans and Vugts (1993)) which is useful to validate a model. Moreover, the MAR snow model was already validated during these years by Lefebre et al. (2003) at ETHCamp and comparison with in situ observations over Greenland during the 1991 ablation season was performed by Lefebre et al. (2004). We evaluate here the modelled precipitation and compare the melt zone and the surface albedo simulated by MAR with satellite remote sensing observations. Satellite data cover the whole ice sheet and provide validation over the entire model domain, in contrast with sparse local observations. Remote sensing of the polar regions since the late seventies provides researchers with a continuous temporal and spatial data set to investigate the physical characteristics of the poorly accessible ice sheet surface.

[4] Section 2 describes the coupled atmosphere-snow RCM and the simulation setup. A description of the satellite data used in this intercomparison is given in section 3. In section 4 we evaluate the 1990 modelled precipitation with coastal weather station 
observations, results from other models (Bromwich et al. (2001), Dethloff et al. (2002)) and with the ERA-40 reanalysis. We compare the microwave melt signal from Special Sensor Microwave/Imager (SSM/I) data (Abdalati and Steffen, 1997) and the surface albedo derived from the Advanced Very High Resolution Radiometer (AVHRR) data set (Fowler et al. (2000)) with the MAR simulation in section 5. Remarks on the model performance and the interest of using a regional climate model to detect bias in satellite derived data and to improve the retrieval algorithms are discussed in the conclusion.

\section{Regional climate model MAR}

\subsection{Model overview}

[5] The model used here is the RCM MAR (Modèle Atmosphérique Régional) coupled to the Surface Vegetation Atmosphere Transfer scheme SISVAT (Soil Ice Snow Vegetation Atmosphere Transfer). The atmospheric part of MAR is fully described in Gallée and Schayes (1994) and Gallée (1995), while the SISVAT scheme is detailed in De Ridder and Gallée (1998) and Gallée et al. (2001).

[6] MAR is a hydrostatic primitive equation model in which the vertical coordinate is the normalized pressure $\sigma=\left(p-p_{t}\right) /\left(p_{s}-p_{t}\right)$ where $p, p_{t}$ and $p_{s}$ are respectively the actual pressure, the constant model top pressure and the surface pressure. The solar radiation scheme is that of Fouquart and Bonnel (1980). The longwave radiation scheme follows a wide-band formulation of the radiative transfer equation (Morcrette, 1984). The hydrological cycle based on the Kessler (1969) and Lin et al. (1983) parameterizations is fully described in Gallée (1995). The boundaries are treated according to a dynamic relaxation scheme that includes a Newtonian term and a diffusion term (Davies, 1983 ; Marbaix et al., 2003). The parameterization scheme for the surface layer is based on Businger (1973) and Duynkerke (1991) formulations. In view of the complex structure of the 
katabatic layer, the E- $\epsilon$ order closure from Duynkerke (1988) is used. Finally, the convective parametrization is that of Bechtold et al. (2001).

[7] Sea Surface Temperatures (SST) are prescribed according to Reynolds and 111 Smith, (1994). They are used to deduce sea-ice distribution. Sea-ice temperatures are computed with SISVAT scheme. The soil-vegetation module of SISVAT is used over the tundra. It is detailed in De Ridder and Schayes (1997) and Gallée et al. (2001, 2004).

114 It simulates the heat and moisture exchanges over land in the case of a snow-free surface (with an albedo of 0.15). The snow-ice module of SISVAT is used in the case of snow deposition on the tundra, the sea ice, or the ice sheet.

117 [8] The snow-ice module is a multi-layered energy balance one-dimensional snowice model and determines the exchanges between the sea ice, the ice sheet surface, the snow covered tundra, and the atmosphere. Its physics and validation are described in de-

120 tails in Gallée and Duynkerke (1997), Gallée et al. (2001), and Lefebre et al. (2003). In particular, the surface albedo is a function of (i) the simulated snow grain form and size represented by the CROCUS snow metamorphism laws (Brun et al., 1992), (ii) the snow depth and (iii) the cloudiness. In case all snow has melted away in the ablation zone, the meltwater accumulated upon the ice lowers the surface albedo below the ice albedo (fixed to 0.55, Van de Wal and Oerlemans, 1994).

\subsection{Model setup}

[9] The simulation starts in September 1989 and ends in December 1991 without reinitialization, contrary to Cassano et al. (2001). We use the ERA-40 reanalysis to initialize the meteorological fields on 1 September 1989 and to force the MAR lateral boundaries every 6 hours. A linear interpolation is made in between. We start the simulation at the end of the previous summer to reduce the problem of snow model initialization as 132 pointed out by Lefebre et al. (2004). The domain (see Figure 1) covers the whole of 
Greenland at a horizontal resolution of $25 \mathrm{~km}$. It is a good compromise between the computing time and a reasonable representation of the different SMB zones. The MAR topography and the soil mask for Greenland are based on Bamber et al. (2001). The initial location of the Equilibrium Line Altitude (ELA), i.e., the boundary between the ice sheet ablation zone and the percolation zone is based on Zwally and Giovinetto (2001). The percolation and the dry snow zones are initialized by $10 \mathrm{~m}$ of no-dendritic snow, and in the ablation zone, an ice pack is prescribed in the ablation zone at the beginning of the simulation (see Lefebre et al. (2004) for more details). Later, the snow pack 141 evolves during the simulation. In this short simulation, the location of the mass balance zones quoted in the text is fixed and comes from the initialization.

\section{Figure 1}

\section{Satellite data}

[10] We present here the satellite data used in section 5 to evaluate the melt and the surface albedo simulated by MAR. The remote melt signal comes from the SSM/I data set (Armstrong et al., 1994) and the surface albedo is derived from the AVHRR data set (Fowler et al., 2000) available from the NSIDC.

\section{1. $\mathrm{SSM} / \mathrm{I}$ passive microwave melt signal}

[11] Liquid water forms in the snow pack when snow melts. It changes dramatically the snow microwave emissions to approach blackbody behaviour (Ulaby and Stiles, 1980). This change in emission characteristics appears clearly in the satellite microwave data. Algorithms can derive very effectively the melt extent over the ice sheet (Mote et al., 1993; Mote and Anderson, 1995; Abdalati and Steffen, 1995 and 1997). In contrast to visible remote sensing, microwave remote sensing offers the advantage of not being 
strongly affected by clouds, cloud shadows, haze and ground fog as well as the extended polar night when visible image collection is unavailable.

\subsubsection{Data}

[12] To evaluate the MAR simulated melt zone, we use here the interpolated melt fields from Abdalati and Steffen (1997) based on data from the SSM/I on the Defense Meteorological Satellite Program (DMSP) F-8 satellite. Combined with satellite data

162 from the Scanning Multichannel Microwave Radiometer (SMMR), this data set is continuously available since 1979 and the images are provided with a horizontal resolution of $25 \mathrm{~km}$. This unique remote sensing data set, which is now 24-year long, enabled Ab-

165 dalati and Steffen (2001) to study the melt extent evolution of the last 21 years over the whole Greenland ice sheet. Their results show a slight positive melt extent trend of $1 \%$ year $^{-1}$.

\subsubsection{Methodology}

[13] The approach of Abdalati and Steffen $(1995,1997)$ is used here to deduce the melt extent over the ice sheet from the SSM/I data. It is based on the cross-polarized gradient ratio (XPGR), which is defined as the normalized difference between the 19GHz horizontal channel and the 37-GHz vertical channel:

$$
X P G R=\frac{T_{b}(19 \mathrm{H})-T_{b}(37 \mathrm{~V})}{T_{b}(19 \mathrm{H})+T_{b}(37 \mathrm{~V})}
$$

174 where $T_{b}$ equals the brightness temperature which is defined as the product of the physical surface temperature and the microwave emissivity. A XPGR threshold value (XPGR > -0.0158) is then used to distinguish melt from non-melt points. This threshold

177 value was determined by Abdalati and Steffen (1995) with in situ measurements of liquid water content (LWC) at ETH-Camp during summer of 1990, 1991, 1993 and 1994. It corresponds approximately to a LWC of $1 \%$ by volume in the top metre of snow (Abdalati and Steffen, 1997). 
[14] The DMSP F-8 satellite which carried the SSM/I sensor in 1990-1991 flew over the Greenland ice sheet early morning at about 0600 LT on descent and late afternoon at about $1800 \mathrm{LT}$ on ascent when the melt is maximum. A daily average XPGR value was calculated from those two signals before processing the SSM/I data. Therefore, the daily SSM/I derived melt signal could result in an overestimation of the melt region considering that the afternoon melt can mask the night-time refreezing. This is an issue especially at the beginning and at the end of the melt season when the melt period may last only a few hours during the mid to late afternoon.

189 [15] To compare the model results with the satellite derived melt area, the daily average modelled LWC of the top metre of snow is used instead of the surface temperature. The surface temperature variable is often used to detect the modelled melt area. But

192 preliminary analysis of MAR output showed that the use of this variable would lead to an unrealistic determination of the simulated melt area compared to XPGR, because this algorithm is sensitive to both surface and sub-surface melt water. At the beginning of the ablation season, the surface temperature is a good indicator because the melt water is mainly situated at the surface. But in late summer, a cold front or a clear night can refreeze the surface while the subsurface remains wet, which is classified as wet by XPGR until the snow is frozen at greater depths. According to Abdalati and Steffen (1997), we use a mean LWC of $1 \%$ by volume as a threshold value to distinguish melt from nonmelt points in the simulation. The bare ice in the ablation zone is assumed to be wet.

\subsection{AVHRR derived surface albedo}

[16] As the surface albedo depends on the nature of the snow, its grain size, water content and thickness, it is therefore an excellent indicator of the snow pack properties. In addition, it is one of the most critical parameters of the surface energy equation since most energy needed for melting is supplied by solar radiation. So far only the surface al- 
bedo from some weather stations on the ice sheet has been used to validate a model (Bugnion and Stone, 2002, Lefebre et al., 2004)). We compare in this paper the modelled surface albedo with the surface albedo derived from the AVHRR Polar Pathfinder (APP) data set (Fowler et al., 2000). This is based on the Advanced Very High Resolu-

210 tion Radiometer (AVHRR) flown on the National Oceanic and Atmospheric Administration (NOAA) operational meteorological satellites (in our case from NOAA 11). However, the latter are only valid in clear-sky cases, which limits the comparison.

\subsubsection{Data}

[17] Here we use the AVHRR Polar Pathfinder Twice-Daily $5 \mathrm{~km}$ Equal Area Scalable Earth-Grid Composites product (Fowler et al., 2000) available from the National

216 Snow and Ice Data Center (NSIDC). This data set includes channel reflectances (channels 1 and 2 in visible and near-infrared), brightness temperatures (channels 3-5 in infrared), clear sky surface temperature and albedo, solar zenith angle, satellite elevation 219 angle, sun-satellite relative azimuth angle, cloud and surface mask, and time information. These products are available twice a day (approximately 0400 UTC and 1400 UTC) at $5 \mathrm{~km}$ resolution using global area coverage (GAC) data for the period July 2221981 through December 2000. They are fitted to the Equal Area Scalable Earth-Grid (EASE-grid) (Armstrong and Brodzik, 1995). This data set is used in Stroeve (2001) to study albedo variability of the Greenland ice sheet from 1981 to 1998.

\subsubsection{Methodology}

[18] The methodology used by the APP product team to derive surface temperature, albedo and cloud masking is based on the Cloud and Surface Parameter Retrieval (CASPR) system (Key, 1999; Key et al., 2001). In brief, the retrieval of clear-sky surface albedo involves the following four steps:

1. normalization of AVHRR channels 1 and 2 with respect to the solar zenith angle; 
2. conversion of the calibrated channels 1 and 2 reflectances to a top-of-the-atmosphere (TOA) broadband reflectance;

3. correction of the dependence of the sun-satellite-surface geometry on TOA broadband 234 reflectance, using an anisotropy factor;

4. conversion of the TOA broadband reflectance to a surface broadband albedo, using a linear relationship;

237 For more detailed information on the derivation of the surface albedo, we refer to Key (1999), Stroeve et al. (2000) and Stroeve (2001). See also Fowler et al. (2000).

[19] In contrast with microwave data, the current algorithm for retrieval of surface 240 albedo is only valid during clear-sky periods. This makes the cloud detection critical. Clouds over Greenland are particularly hard to detect in the infrared part of the spectrum because their temperature is often similar to that of the surface. Three cloud masks using

243 a combination of time series analysis and multichannel threshold tests are provided in the $5 \mathrm{~km}$ APP products. One is based on multichannel and multiday techniques in the CASPR algorithms; another is obtained by using a long time series of channel 4; and a third is a modified method of replacing the channel 4 statistic required in the CASPR algorithm with the channel 4 series from the second method. These three methods are described in more detail in Stroeve (2001).

[20] Following the recommendations of Stroeve (2001), the second cloud mask (based on a temporal thermal filter) is used here to detect clouds. The other two cloud masks tend to overestimate clouds over Greenland (Stroeve, 2001). However, the cloud detection remains imperfect and an albedo filter is applied to discard pixels with a too low albedo or an albedo greater than 1.0. We consider that the minimum albedo is 0.15 in the tundra area, 0.3 in the ablation zone, 0.6 in the percolation zone and 0.7 in the dry snow zone. The albedo of dry snow varies generally between 0.8 and 0.9 (Wiscombe 
and Warren, 1980), the wet snow albedo between 0.6 and 0.8 and the bare ice albedo between 0.3 and 0.55 (depending on the liquid water present at the surface). The APP surface albedo is interpolated on the $25 \mathrm{~km}$ MAR grid for a better comparison with MAR results and the gaps due to the presence of clouds are filled by interpolation. The daily MAR albedo is defined as the ratio of the daily total short-wave reflected radiation and global radiation. It is clear that the i) cloud detection, ii) the estimation of APP parameters at extreme viewing angle and iii) the interpolation of clear skies to cloudy areas can result in a large source of uncertainty in the current estimates of surface albedo us264 ing AVHRR data.

\section{Evaluation of Precipitation}

[21] Precipitation directly influences the Surface Mass Balance (SMB) by adding snow or liquid water to the ice sheet. It also conditions the appearance of the low albedo zones in summer such as the tundra and the bare ice in the ablation zone. This has direct impact on the melt intensity. Mote (2003) further concludes that low ablation years are more likely associated with high winter accumulation. The precipitation needs therefore to be modelled as accurately as possible to be able to study the entire SMB of the Greenland ice sheet. Here, we evaluate the MAR precipitation in 1990. The conclusions are 273 the same for 1991.

\subsection{Data}

[22] Direct precipitation measurements are mostly collected on the coast by the Dan276 ish Meteorological Institute (DMI) weather stations and are often influenced locally by wind effects and snow drift during snowfall. Therefore they are not really representative for the Greenland ice sheet conditions. For these reasons, their use is not sufficient to

279 validate a model at the scale of the whole Greenland. On the other hand, the classical climatologies based on extrapolated weather station measurements are not so useful in 
Greenland. Ice core measurements (see Figure 2 in Kiilsholm et al., 2003) show an accumulation of $300-500 \mathrm{~mm} /$ year at the top of the ice sheet in the South and along the North-West of the ice sheet. In the North-East, the accumulation is about $100 \mathrm{~mm} / \mathrm{year}$. None of the three climatologies plotted on Figure 2 shows this pattern. The climatologies agree better with observations along the coasts. Hence, our option is also to use other (regional) models to assess the precipitation simulated by MAR. To do so, we use the modelled precipitation from i) Bromwich et al. (2001) (noted B01 here after), ii) results

288 from the regional climate model HIRHAM4 (Dethloff et al., 2002) and iii) the forecast precipitation from ERA-40 data set. This later is obtained from the $12-24 \mathrm{~h}$ period of each forecast. The B01 data set is available at a resolution of $50 \mathrm{~km}$ and is based on a 291 statistical-dynamical and topographic forcing of precipitation (Chen et al., 1997) using ERA-15 reanalysis. It was successfully validated with measured accumulation from 11 ice core sites. Cassano et al. (2001) used these data to validate Polar MM5 simulations 294 on Greenland and recently Mote (2003) estimated the Greenland ice sheet SMB with the same data set.

\subsection{Results}

[23] Table 1 lists for 12 coastal DMI weather stations (shown on Figure 1) the cumulated total precipitation in 1990 observed and simulated by the four models cited above. The DMI data and the HIRHAM4 outputs are from Dethloff et al. (2002). The B01 and ERA-40 values come from an interpolation on the MAR grid and are taken at the grid points closest to the stations. MAR agrees very well with other models, and is even the closest to the observations (see the RMSE in Table 1). In view of the weather station sites, the assessment of the models ability to reproduce precipitation is limited to the Greenland coasts while the aim of these models is to study the ice sheet mass bal- 
ance. Moreover, these observations are very likely marred by biases because it is very difficult to measure snowfall with standard precipitation gauges.

\section{Table 1}

[24] Figure 2 shows than simulated amount and distribution of precipitation is comparable to that of B01 and ERA-40 in 1990, except in southern Greenland. MAR simulates $111 \%$ of the $\mathrm{B} 01$ precipitation and $99 \%$ of the ERA-40 precipitation on average over Greenland. Precipitation occurs mainly along the western and southeastern coast in the three models. There is a minimum in north central Greenland where it is known that the annual accumulation is smaller than $200 \mathrm{~mm} \mathrm{yr}^{-1}$ (Dethloff et al., 2002). Maxima of precipitation are found in the far south and along the eastern coast of Greenland in the 315 MAR model, ERA-40 reanalysis, CRU (New et al., 2000) and GPCC 1990-climatologies and in the Dethloff et al. (2002) estimations (see their Figure 4). Bromwich et al. (2001) simulates two maxima of precipitation respectively along southwestern and

318 southeastern coasts, and comparatively little precipitation in the far south of Greenland. The same occurs in 1991 (not shown here). The local minimum of precipitation simulated by MAR in southern Greenland near Narsarsuaq (See Figure 1) is also present in the Dethloff et al. (2002) estimation (their Figure 4). MAR overestimates precipitation above the ice sheet (South-Dome and Summit regions) when compared with both other models and Dethloff et al. (2002) estimations. MAR simulates also much more precipitation than the other models along the eastern coast and steep windward margins. However the location of the MAR maxima agrees very well with that of the others models (particularly the ERA-40 reanalysis). The analysis of the MAR precipitation in 1991 shows the same overestimations as in 1990. This is associated with the "topographic barrier effect" which modifies the horizontal flow, or contributes to raise air masses and to produce condensation and thus precipitation during their forced ascent (Brasseur et 
al., 2001). This excessive precipitation is also present in the Polar MM5 model simulations (Cassano et al., 2001) and HIRHAM4 model (Dethloff et al., 2002). To reduce this error, MAR should be coupled with a rain disaggregator model (denoted RDM) as described in Brasseur et al. (2001). A RDM takes into account a more accurate representation of the subgrid orography (notably the presence of valleys), which reduces the topography barrier effect (Sinclair, 1994).

\section{Figure 2}

\section{MAR and satellite observations}

[25] The melt zone intercomparison between MAR and SSM/I derived data is lim339 ited to the ablation period, i.e. May-September. The same limitation is applied to the assessment of the surface albedo because it remains constant (about $0.8=$ dry snow albedo) during the other seasons.

\subsection{Melt zone}

[26] The satellite derived melt extent evolution is plotted in Figures 3a and 4a together with the modelled daily melt average during the 1990 and 1991 summers. Three different threshold values (represented by the error bar) are used to detect melt in the MAR snow pack: a LWC of $0.5 \%$ (upper limit of the error bar), $1 \%$ (the solid curve) and $1.5 \%$ (lower limit of the error bar) in the top metre of snow. The timing and amplitude of the simulated melt compare generally well with the Abdalati and Steffen (1997) data. In 1990 and 1991, the melt season begins at the end of May and ends at the beginning of October with respectively a maximum in early August 1990 and in midJuly 1991. Secondary maxima, respectively in mid-July 1990 and the first week of June 1991, also agree with the derived satellite data set.

\section{Figures 3 \& 4}


[27] The satellite derived melt signal is extremely low on several occasions, i.e. July $22-27^{\text {th }} 1990$, August 5-7 1990 , June $26-29^{\text {th }} 1991$, August $3^{\text {rd }} 1991$ (Figures $3 a$ and $4 a$ ) by comparison with MAR. The SSM/I derived melt pattern does not show melt in the southwestern ablation zone during these periods (see also Figure 5). This is most likely an error in the satellite estimates since the southwestern melt zone is at a lower elevation than the southeastern one. Moreover, melt was observed in the southwest region just be360 fore and after this period (Figure 5c). One possible explanation for this bias is the occurrence of rainfall events on the ice sheet. Indeed, significant liquid precipitation events (see Figures $3 b$ and $4 b$ ) occurred along the Greenland western coast. They are associated with the presence of a low pressure in Labrador Sea and coincide with the secondary minima in the satellite derived melt extent. For example, on 26 July 1990 and 27, 29 of June 1991, 19 and 21, $8.5 \mathrm{~mm}$ W.E. of rainfall were respectively observed at ETH366 Camp, West Greenland (Ohmura et al., 1992). This type of circulation, called barriertype flow, tends to increase ablation on the ice sheet (Van den Broeke and Gallée, 1996). This leads us to conclude that "no melt" in the western ablation zone during this period is unrealistic. This hypothesis is confirmed by Figure 3c (resp. 4c) and Table 2. MAR and SSM/I derived data are much more consistent during these rainfall days when these zones are not considered. The zones where MAR simulates precipitation higher than $1 \mathrm{~mm} /$ day (Figure 5 bottom) correspond with the zones where satellite derived data do not detect melt. Note that such a problem was pointed out by Eppler et al. (1992) who mention that sea-ice concentration retrieval from passive microwaves becomes unreliable during precipitation events larger than $10 \mathrm{~mm} /$ day.

[28] In polar regions, optically thick clouds are scarce and neglecting their influence in passive microwave analysis is generally a good approximation. Currently, none of passive microwave melt algorithms have included atmospheric variability. The normal- 
ized nature of the XPGR method should mitigate the impact of cloud cover. Although the 19-GHz channel is the less sensitive to the atmospheric influence (rainfall events), it is not the case for the $37-\mathrm{GHz}$ channel used also in the XPGR method. Chevallier and Bauer (2003) use the latter to detect rainfall over oceans. All future passive microwave analysis and/or algorithms to derive melt should try to incorporate atmospheric variability especially during rainfall events.

\section{Table 2 \\ Figure 5}

[29] Figures 6 and 7 compare the total number of ablation days simulated by MAR (Figures $6 a$ and $7 a$ ) with the satellite-derived estimates (Figures $6 \mathrm{~b}$ and $7 \mathrm{~b}$ ) during the period May-September in 1990 and 1991. The dotted line on the SSM/I plots shows the

390 MAR ice sheet margin to enable a better comparison between both melt fields. Melt distributions are very consistent with the satellite estimates for both years and the melt is well limited to the ablation and percolation zones. Although the ice sheet masks are not

393 the same, there are clearly less melt days in Abdalati and Steffen (1997) fields along the ice sheet margin than in MAR. These low altitude regions are the most sensitive to rainfall events that shadow the melt signal in Abdalati and Steffen (1997) fields as shown before. Therefore, this data set underestimates melt in those zones.

[30] MAR underestimates melt along the (south)eastern mountain chain summits, as the ECHAM 4 model (Bugnion and Stone, 2002). On the one hand, MAR overestimates (solid) precipitation in this region. This decreases the LWC in the snow pack, raises the albedo and therefore reduces the melt. In view of the altitude of this region, no rainfall events are simulated. On the other hand, the satellite-derived values may constitute an overestimation of melt in the high percolation area. The threshold LWC value of $1 \%$ in top metre of snow to detect melt was only validated at ETH-Camp in the ablation zone 
and should be compared with in situ data from a site located in the higher percolation area. The snow pack characteristics in the ablation zone differ a lot from those in the percolation zone and a similar LWC could have a different melt signal. Table 2 and the error bars in Figures 3a and 4a highlight the importance of the choice of the melt threshold value. In addition, as pointed out by Torinesi et al. (2003), the microwave brightness temperature could be biased by numerous rock outcrops (boulders) found in this mountainous region.

\section{Figures $6 \& 7$}

\subsection{Surface albedo}

[31] The surface albedo observed at ETH-Camp in 1991 (Ohmura et al., 1992), de414 rived from APP products and simulated by MAR is shown in Figure 8. Small-scale oscillations in AVHRR in Figure 8a fields are a known artifact in the APP products (Stroeve, 2001). The comparison between these two plots supports our interpolation method 417 of APP products to the MAR grid. Figure $8 \mathrm{~b}$ also confirms the ability for MAR to simulate the surface albedo at ETH-Camp (see also Lefebre et al., 2004).

\section{Figure 8}

[32] In Figures 9 and 10 are plotted the time evolution of the surface albedo averaged in 1990 and 1991 over the four zones shown in Figure 1: a) the ablation zone, b) the percolation zone, c) the dry snow zone, and d) the tundra.

423 a) As observed in Figures 3 and 4, the surface melt starts at the end of May in the ablation zone in 1990 and 1991. This is in good agreement with the beginning of the albedo decrease (Figures 9a and 10a). The sharp transition from a dry snow pack in May to a wet snow pack in June is clearly visible in 1991. This metamorphism is more gradual in 1990. The albedo variations in June are associated with snow falls that temporarily raise the snow albedo. Bare ice (albedo lower than 0.55) begins to 

appear from the end of June and the albedo continues to decrease to reach the minimum value at the beginning of August, when the snow pack has completely melted in many places. Two significant snowfall events found in both AVHRR and MAR fields at the end of July and at the beginning of August in southeastern Greenland temporarily increase the mean ablation zone albedo in 1991. At the end of August 1990 and in mid-August 1991, the melt season is over and fresh snow begins to cover the bare ice. Then the albedo increases to reach the typical value of dry snow at the beginning of September. During summer months, MAR overestimates the albedo compared to that derived from satellite. Firstly the cloud contamination in APP fields tends to underestimate snow albedo. Secondly MAR can overestimate the snow pack height in some places because of overestimated snowfalls as shown in Table 1. Therefore, this restores the appearance of bare ice (with a lower albedo) in the abla441 tion zone (Lefebre et al., 2004). Thirdly, the AVHRR albedo values may constitute an underestimation. Stroeve et al. (2000) mention that the APP albedo values are on average $10 \%$ less than those measured by AWS stations from January 1997 to August 1998. This bias can be reduced to $6 \%$ considering that the ground-based measurements are also biased.

b) In the percolation zone, there is a small albedo decrease associated with the moistening of the snow pack in June and July. But no bare ice appears and the albedo remains above 0.7 .

c) The snow pack remains dry in the dry snow zone (Figures 9c and 10c) and therefore no significant variations are observed. The very small variations in AVHRR albedo are most likely due to cloud contamination. For example, stratospheric clouds (di Sarra et al., 2002) are abundant over the Greenland ice sheet summit but are not detected by the CASPR algorithm. 
d) The albedo evolution in the tundra area (Figures 10d and 11d) is similar to that in the ablation zone with dry snow that becomes wet snow at the beginning of spring. A grass surface appears in August once all snow has melted away. A wet snow pack again covers the soil at the end of summer. MAR overestimates (underestimates) the albedo in May and June (in August and September). Besides a possibly overestimated MAR snow pack at the beginning of the spring, very few corrections are applied to the satellite derived albedo in the tundra (albedo minimum $=0.15$ ). It is likely that errors in the cloud mask significantly bias the APP fields in this often cloudy region located near the coast. These errors lower the derived albedo when the soil is covered with snow and raise it when all the snow has melted over the grass. The cloud contaminated albedo varies generally between 0.3 and 0.7 and therefore is higher than the grass albedo (0.15) and lower than the snow albedo (0.6-0.8).

\section{Figure $9 \& 10$}

[33] Figures 11 and 12 illustrate the albedo evolution through the four summer months, i.e. (i) the transition from dry snow albedo to wet snow albedo first in the tundra and ablation zone (May) and afterwards in the percolation zone (June), (ii) the drop in the albedo due to the complete melt of the snow pack above soil in the tundra and ice in the ablation zone (July), iii) the progressive increase of albedo at the summer end (August) because of new snowfalls. As explained earlier, MAR overestimates albedo on the tundra when compared to the AVHRR estimates.

[34] In conclusion the retrieval of the snow surface albedo from satellite data is useful for validating MAR over the ice sheet, but is difficult to interpret in cloudy areas.

\section{Figure $11 \& 12$}




\section{Conclusion and discussion}

[35] The evaluation of three SMB parameters (precipitation, melt and albedo) simulated by the coupled atmosphere-snow regional climate model MAR has been presented for both the 1990 and 1991 ablation seasons over Greenland. MAR was nested into ERA-40 reanalysis with an update every 6 hours without reinitialization. The simulation starts at the end of the previous summer (the $1^{\text {st }}$ of September 1989) to reduce the impact of the snow pack initialization on the results. The accumulation of the 1989-1990 winter is therefore simulated explicitly. Indeed previous simulations initialized on the $1^{\text {st }}$ of May 1990 showed a very large sensitivity to the initial conditions used in the snow model. The results are particularly sensitive to the initial snow height and the snow properties above the tundra and the ablation zone because of the albedo feedback (Lefebre et al., 2004). Precipitation has been compared with in situ observations and with results from other models. Simulated melt days and albedo have been evaluated with SSM/I-derived data (Abdalati and Steffen, 1997) and AVHRR albedo (Fowler et al., 2000) respectively.

492 [36] MAR simulated precipitation agrees well in quantity and distribution with results from i) the regional model HIRHAM4 (Dethloff et al. (2002)), ii) the model from Bromwich et al. (2001) and iii) the ERA-40 reanalysis. When we compare all four models with the observations from the DMI coastal weather stations, MAR is the closest to the observations. However, MAR overestimates precipitation in southern Greenland along the steep margins of the Greenland ice sheet, similarly to the Polar MM5 model (Cassano et al., 2001), and above the ice sheet near the South Dome. This is most likely associated with the "topographic barrier effect" (Brasseur et al., 2001). This should be investigated in the future by coupling MAR model with a rain disaggregator model. 
[37] The simulated extent and time evolution of the wet snow zone is compared with SSM/I-derived data (Abdalati and Steffen, 1997). MAR underestimates melt along the southeastern mountain range, likely because of excessive simulated snowfall. On the other hand, the presence of nunataks in this region biases the remote sensing signal. Melt retrieval algorithm detects very little melt compared to MAR along the ice sheet margin. In fact rainfall events were found to perturb the satellite melt signal. This leads to underestimated melt in SSM/I-derived data, especially in these low altitude regions. In addition, the threshold LWC value of $1 \%$ in the top metre of snow to detect melt in MAR fields was only validated at ETH-Camp situated in the ablation zone and should 510 therefore be further validated, e.g. for a higher percolation zone site. Future passive microwave analysis algorithms used to derive melt should incorporate atmospheric variability (as for example rainfall) that currently bias their results. An atmospheric model running at a sufficiently fine resolution could be used, to detect rainfall events on the ice sheet and to improve melt retrieval algorithms.

[38] The comparison with AVHRR data enabled the validation over the whole ice 516 sheet of (i) the modelled surface albedo, (ii) the snow pack evolution and (iii) the snow accumulation simulated by MAR. If the simulated snow pack height is too high at the beginning of the summer, it delays the appearance of low albedo zones, such as grass in the tundra, and bare ice in the ablation zone, with an impact on the SMB. MAR snow pack evolution agrees generally with AVHRR data. The satellite derived albedo is probably still too contaminated by clouds over the tundra despite the cloud mask. The cloud detection, correction and interpolation in the AVHRR data remain unfortunately a large source of uncertainty in this comparison.

[39] Satellite data offer many advantages: continuous cover of ice sheet in time and space, compared to in situ observations, to validate models results. But, the comparison 
with MAR results also highlighted the large effect of weather conditions. Once validated, a model like MAR could be used to detect and correct bias in satellite derived data and to make new improved retrieval algorithms taking into account atmospheric variability.

[40] Currently, the satellites easily detect the melt but not the melting volume.

531 However, it is more and more necessary to estimate accurately the fresh melt water flux from Greenland to study its impact on the Atlantic Ocean circulation and on sea level rise. In view of the good agreement of the MAR simulated melting surface with the im-

534 proved satellite signal, MAR could provide a detailed estimation of the melting volume.

\section{Acknowledgments}

[41] Xavier Fettweis is a research fellow of the Belgian National Fund for Scientific Research. Comments by Prof. Roger Barry helped improve the manuscript. The authors acknowledge the National Snow and Ice Data Center (NSIDC, Boulder, Colorado) for providing the Bamber et al. (2001) topography, the Bromwich et al. (2001) precipitation 540 data sets, the SSM/I data (Abdalati and Steffen, 1997) and the AVHRR Polar Pathfinder Twice-Daily 5 km EASE-Grid Composites products (Fowler et al., 2000) (see http://nsidc.org/). The project was supported by the French programme ACI-C3 (Min543 istère de la Recherche). All major computations were realized with IDRIS computing resources (France). 


\section{References}

Abdalati W., and K. Steffen (1995) Passive microwave-derived snow melt regions on the Greenland ice sheet. Geophys. Res. Lett., 22, 787-790.

Abdalati W., and K. Steffen (1997) Snowmelt on the Greenland ice sheet as derived from passive microwave satellite data. J. Climate, 10, 165-175.

Abdalati W., and K. Steffen (2001) Greenland ice sheet melt extent: 1979-1999. J. Geophys. Res., 106, 33983-3389.

Armstrong, R.L., K.W. Knowles, M.J. Brodzik and M.A. Hardman (1994) DMSP SSM/I Pathfinder daily EASE-Grid brightness temperatures, May to September 1990 \& 1991. Boulder, CO: National Snow and Ice Data Center. Digital media and CD-ROM.

Armstrong, R. L., and M. J. Brodzik (1995) Earth-gridded SSM/I data set for cryospheric studies and global change monitoring, in A 1 Symposium of COSPAR Scientific Commission A, Hamburg, Germany, July 11-21, 1994. Proceeding, Satellite monitoring of the earth's surface and atmosphere, Nov. 1995, pp. 115-116.

Brasseur O., H. Gallée, J.-D. Creutin, T. Lebel , and P. Marbaix (2001) High resolution simulations of precipitation over the Alps with the perspective of coupling with a hydrological model. Advances in Global Change Research, 10 (M. Beniston, Ed.), 75-100.

Bamber, J. L., R.L. Layberry, and S.P. Gogineni (2001) A new ice thickness and bed data set for the Greenland ice sheet: part I, Measurement, data reduction, and errors, J. Geophys. Res., 106, 3377333780.

Bechtold, P., E. Bazile, F. Guichard, P. Mascart and E. Richard (2001) A mass flux convection scheme for regional and global models, Q. J. R. Meteorol. Soc., 127, 869-886.

Box, J. E., and A. Rinke (2003) Evaluation of Greenland ice sheet surface climate in the HIRHAM regional climate model, J. Clim., 16, 1302 -1319.

Box, J.E., D. H. Bromwich, L-S Bai, 2004: Greenland ice sheet surface mass balance for 1991-2000: application of Polar MM5 mesoscale model and in-situ data, J. Geophys. Res., Vol. 109, No. D16, D16105, 10.1029/2003JD004451.

Bromwich, D. H., Q. Chen, L. Bai, E. N. Cassano, and Y. Li (2001) modelled precipitation variability over the Greenland ice sheet. J. Geophys. Res., 106, 33891-33908. 
Brun, E., P. David, M. Sudul, and G. Brunot (1992) A numerical model to simulate snowcover stratigraphy for operational avalanche forecasting. J. Glaciol., 38, 13-22.

Bugnion, V. and P.H. Stone (2002) Snowpack model estimates of the mass balance of the Greenland ice sheet and its changes over the twenty first centuy, Climate Dynamics, 20, 87-106.

Businger, J. (1973) Turbulent transfert in the atmospheric surface layer, workshop on micrometeorology. Amer. Meteorol. Soc., 67-100.

Cappelen, J., B. V. Jorgensen, E. V. Laursen, L. S. Stannius, and R. S. Thomsen (2000) The observed climate of Greenland, 1958-99, with climatological standard normals, 1961-1990. DMI Tech. rep. 00-18, DMI, Copenhage, Danemark, 149pp.

Cassano, J. J., J. E. Box, D. H. Bromwich., L. Li, and K. Steffen (2001) Evaluation of Polar MM5 simulations of Greenland's atmospheric circulation. J. Geophys. Res., 106, 33891-33908.

Chen, Q.-S., D. H. Bromwich, L. Bai (1997) Precipitation over Greenland retrieved by a dynamic method and its relation to cyclonic activity. J. Clim., 10, 839-870.

Chevallier, F. and P. Bauer (2003) Model rain and clouds over oceans: comparison with SSM/I observations, Mon. Wea. Rev., 131, 1240-1255.

Christensen, O. B., J. H. Christensen, B. Machenhauer, and M. Botzet (1998) Very high-resolution regional climate simulations over Scandinavia-Present Climate. J. Climate, 11, 3204-3229.

Davies, H. (1983) Limitations of some common lateral boundary schemes used in regional NWP models. Mon. Wea. rev., 111, 1002-1012.

De Ridder, K. and G. Schayes (1997) The IAGL land surface model. J. Appl. Meteorol., 36, 167-182.

De Ridder, K., and H. Gallée (1998) Land surface-induced regional climate change in Southern Israel. J. Appl. Meteorol., 37, 1470-1485.

Dethloff, K., M. Schwager, J. H. Christensen, S. Kiilsholm, A. Rinke, W. Dorn, F. Jung-Rothenhäusler, H. Fischer, S. Kipfstuhl, and H. Miller (2002) Recent Greenland accumulation estimated from regional model simulations and ice core ananlysis. J. Climate, 15, 2821-2832.

di Sarra, A., M. Cacciani, G. Fiocco, and D. Fua (2002) Lidar observation of polar stratospheric clouds over northern Greenland in the period 1990-1997. J. Geophys. Res., 107, D12, 10.1029/2001JD001074.

Duynkerke, P. G. (1988) Application of the E- $\varepsilon$ turbulence closure model to the neutral and stable atmospheric boundary layer. J. Atmos. Sci., 45, 865-880. 
Duynkerke, P. G. (1991) Radiation fog: a comparison of model simulation with detailed observations. Mon. Wea. rev., 119, 324-341.

Duynkerke, P. G. and M. R. van den Broeke (1994) Surface energy balance and katabatic flow over glacier and tundra during GIMEX-91. Global Planet. Change, 9, 17-28.

Eppler, D., L. Farmer, A. Lohanick, M. Anderson, D. Cavalieri, J. Comiso, P. Gloersen, C. Garrity, T. Grenfell, M. Hallikainen, J. Maslanik, C. M“atzler, R. Melloh, I. Rubinstein, and C. Swift (1992) Passive microwave signatures of sea ice, in Microwave Remote Sensing of sea ice, edited by F. Carsey, Geophysical Monograph 68, chap. 4, American Geophysical Union.

Fouquart, Y. and. B. Bonnel (1980) Computation of the solar heating of the Earth's atmosphere: A new parameterization. Beitr. Phys. Atmos., 53, 35-62.

Fowler, C., J. Maslanik, T. Haran, T. Scambos, J. Key, and W. Emery (2000) AVHRR Polar Pathfinder Twice-Daily 5 km EASE-Grid Composites. Boulder, CO, USA: National Snow and Ice Data Center. Digital media. See also http://nsidc.org/data/docs/daac/nsidc0066_avhrr_5km.gd.html.

Gallée, H. and G. Schayes (1994) Development of a three-dimensional meso- $\gamma$ primitive equations model. Mon. Wea. rev., 122, 671-685.

Gallée, H. (1995) Simulation of the mesocyclonique activity in the Ross Sea, Antartica. Mon. Wea. rev., $123,2051-2069$.

Gallée, H. and P. G. Duynkerke (1997) Air-snow interaction and the surface energy and mass balance over the melting zone of West Greenland during the Greenland Ice Margin Experiment. J. Geophys. Res., 102, 13813-13824.

Gallée, H., G. Guyomarc'h and E. Brun (2001) Impact of the snow drift on the Antartic ice sheet surface mass balance: possible sensitivity to snow-surface properties. Boundary-Layer Meteorol., 99, 1-19.

Gallée, H., W. Moufouma-Okia, P. Bechtold, O. Brasseur, I. Dupays, P. Marbaix, C. Messager, R. Ramel, and T. Lebel (2004) A high-resolution simulation of a West African rainy season using a regional climate model, J. Geophys. Res., 109, D05108, doi:10.1029/2003JD004020.

Giorgi, F., and L. O. Mearns (1999) Regional climate modeling revisited. J. Geophys. Res., 104, 6335630 6352.

Hanna, E., P. Huybrechts, and T. Mote (2002) Surface mass balance of the Greenland ice sheet from climate analysis data and accumulation/runoff models, Ann. Glaciol., 35, 67-72. (2001) IPCC: Climate Change 2001: The Scientific Basis. Contribution of Workings Group I to the 
Third Assessment Report of the Intergovernmental Panel on Climate Change, Cambridge University Press, Cambridge, United Kingdom and New York, NY, USE, 881pp.

Kessler, E. (1969) On the distribution and continuity of water substance in atmospheric circulation, Meteor. Monogr., 84 pp.

639 Key, J. (1999) The cloud and surface parameter retrieval (CASPR) system for polar AVHRR, 59 pp., Coop. Inst. For Meteorol. Satell. Stud., Univ. of Wisc., Madison.

Key, J., X. Wang, J. Stoeve and C. Fowler (2001) Estimating the cloudy-sky albedo of sea ice and snow from space. J. Geophys. Res., 106, 12489-12497.

Kiilsholm, S., Christensen, J. H., Dethloff, K., Rinke, A. (2003) Net accumulation of the Greenland ice sheet: High resolution climate modelling of regional climate change in the Arctic, Geophys. Res. Lett. 30, 1485, doi:10.1029/2002GL015742.

Krabill, W., E. Frederick, S. Manizade, C. Martin, J. Sonntag, R. Swift, R. Thomas, W. Wright and J. Yngel (1999) Rapid thinning of parts of the southern Greenland ice sheet, Science, 283, 1522-1524.

Lefebre, F., H. Gallée, J. van Ypersele, and W. Greuell (2003) Modeling of snow and ice melt at ETHcamp (west Greenland): a study of surface albedo. J. Geophys. Res., Vol. 108 No. D8, 10.1029/2001JD001160.

Lefebre, F., X. Fettweis, H. Gallée, J. van Ypersele, P. Marbaix, W. Greuell, and P. Calanca (2004) Evaluation of a high-resolution regional climate simulation over Greenland. Climate Dynamics (in revision).

Lin, Y.-L., R. D. Farley, and H. D. Orville (1983) Bulk parameterization of the snow field in a cloud model, J. Appl. Meteorol., 22, 1065-1092.

Marbaix, P., H. Gallée, O. Brasseur, and J. van Ypersele (2003) Lateral boundary conditions in regional climate models: a detailed study of relaxation procedure, Mon. Wea. rev., 131, 461-479.

Morcrette, J. (1984) Sur la paramétrisation du rayonnement dans les modèles de circulation générale atmosphérique, Ph. D. Thesis, univ. des Sci. et Tech. de Lille, Lille, France.

Mote, T. L. (2003) Estimation of runoff rates, mass balance, and elevation changes on the Greenland ice sheet from passive microwave observations. J. Geophys. Res., 108(D2), 4056, doi :10.1029/2001JD002032. 
Mote, T. L., M. R. Anderson, K.C. Kuivinen, and C. M. Rowe (1993) Passive microwave-derived spatial and temporal variations of summer melt on the Greenland ice sheet, Ann. Glaciol., 17, 233-238.

Murphy, B. F., I Marsiat, and P. Valdes (2002) Atmospheric contributions to the surface mass balance model of Greenland in the HadCM3 atmospheric model, J. Geophys. Res., 107(D21), 4556, doi:10.1029/2001JD000389.

New M., M. Hulme, P. Jones (2000) Representing twentieth-century space-time climate variability. Part II: Development of 1901-96 monthly grids of terrestrial surface climate, J. of Climate, 13, 2217-2238. Ouchi, D. Steiger, and G. Niederbaumer (1992) Energy and mass balance during the melt season at the equilibrium line altitude, Paakitsoq, Greenland ice sheet: Progress report 2, Dep. of Geography, Swiss Federal Institute of Technology, Zurich.

Oerlemans J, Vugts H (1993) A meteorological experiment in the melting zone of the Greenland Ice Sheet. Bull Amer Meteor Soc 74: 355-365

Pfeffer, W., M. Meier, and T. Illangasekare (1991) Retention of Greenland runoff by refreezing: implication for projected future sea level change. J. Geophys. Res., 96, 22117-22124.

Reynolds, R. W. and T. M. Smith (1994) Improved global sea surface temperature analyses using optimum interpolation. J. Climate, 7, 929-948.

Sinclair, M. R. (1994) A diagnostic model for estimating orographic precipitation. J. Appl. Meteorol., 33, $1163-1175$.

Stroeve, J. (2001) Assessment of Greenland albedo variability from advanced very high resolution radiometer Polar Pathfinder data set. J. Geophys. Res., 106, 33989-34006.

Stroeve, J., J. Box, C. Fowler, T. Haran, and J. Key (2000) Intercomparison between in situ and AVHRR Polar Pathfinder-derived surface albedo over Greenland. Remote Sens. Environ., 75, 360-374.

Stroeve, J., A. Nolin, and K. Steffen (1997) Comparison of AVHRR-derived and in situ surface albedo over Greenland ice sheet. Remote Sens. Environ., 62, 262-276.

Torinesi, O., M. Fily and C. Genthon (2003) Variability and trends of the summer melt period of Antarctic ice margin since 1980 from microwave sensors, J. Climate, 16, 1047-1060.

Ulaby, F. and W. Stiles (1980) The active and passive microwave response to snow parameters. 2: water equivalent of dry snow. J. Geophys. Res., 85: 1045-1049.

Van den Broeke, M.R., P.G. Duynkerke and J. Oerlemans (1994) The observed katabatic flow at the edge of Greenland ice sheet during GIMEX-91. Global Planet. Change, 9, 3-15. 
Van den Broeke, M.R. and H. Gallée (1996) Observation and simulation of barrier winds at the western margin of the Greenland ice sheet. Q. J.R. Meteorol. Soc., 122, 1365-1383.

Van de Wal, R.S.W. and J. Oerlemans (1994) A energy balance model for the Greenland ice sheet. Global 699 Planet. Change, 9, 115-131.

Wiscombe, W. J. and S. G. Warren (1980) A Model for the spectral albedo of snow. I: Pure snow. J. Atm. Sc., 37(12), 2712-2733.

702 Xie, P. and P. Arkin (1997) Global precipitation: a 17-year monthly analysis based on gauge observations, satellite estimates and numerical model outputs, BAMS, 78, 2539-2558.

Xue, Y., S. Sun, D. S. Kahan, and Y. Jiao (2003) Impact of parameterizations in snow physics and interface processes on the simulation of snow cover and runoff at several cold region sites, J. Geophys. Res., 108(D22), 8859, doi:10.1029/2002JD003174.

Zwally, J. H. and M. B. Giovinetto (2001) Balance mass flux and ice velocity across the equilibrium line in drainage systems of Greenland. J. Geophys. Res., 106, 33717-33728.

Zwally, J.H., W. Abdalati, T. Herring, K. Larson, J. Saba, and K. Steffen (2002) Surface Melt-Induced Acceleration of Greenland Ice-Sheet Flow. Science 12 July 2002; 297: 218-222; published online 6 June 2002 [DOI: 10.1126/science.1072708]. 


\section{Table of Contents}

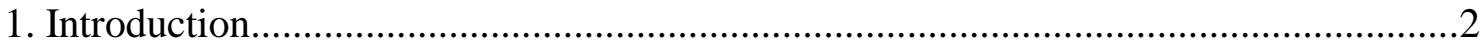

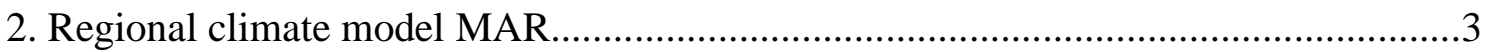

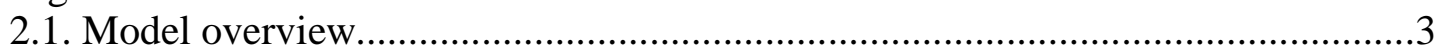

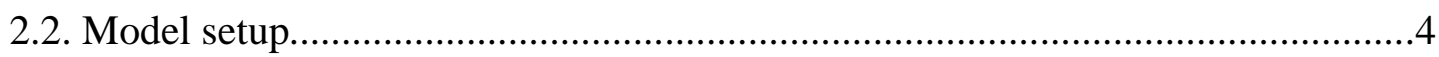

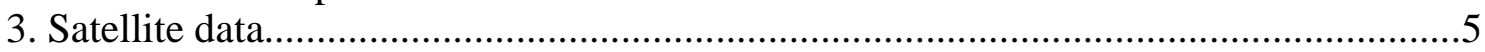

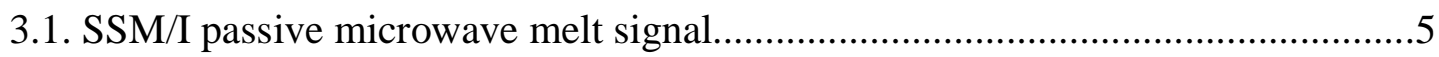

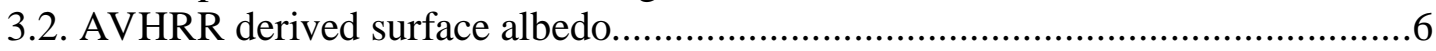

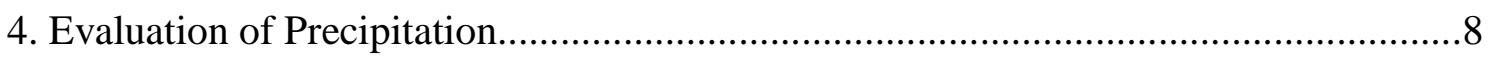

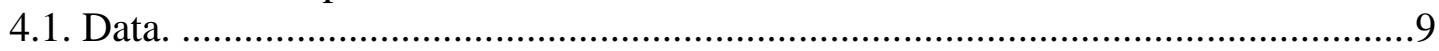

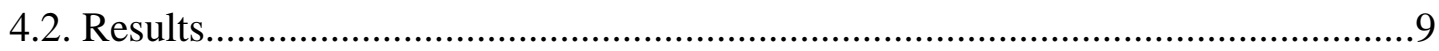

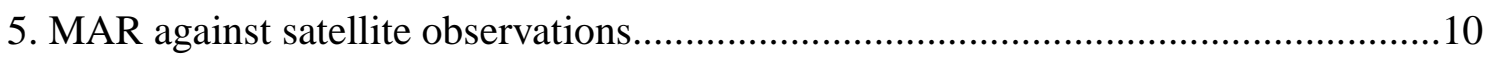

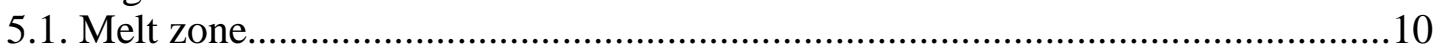

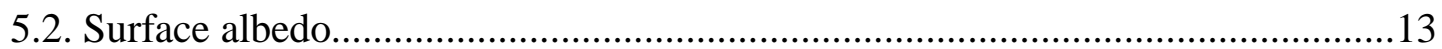

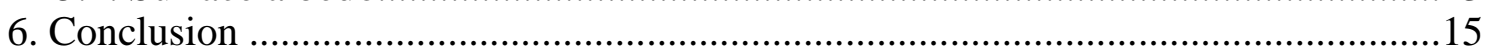

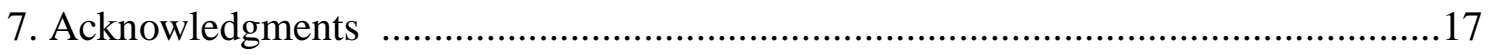

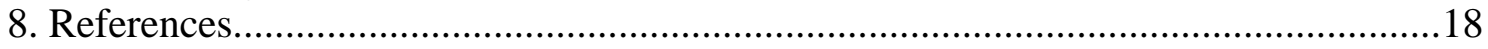


Table 1: Total 1990 precipitation (mm) for Greenland from the Danish Meteorological 714 Institute (Cappelen et al., 2000), ERA-40 reanalysis, MAR simulation, Bromwich et al. (2001) and HIRHAM4 simulations (Dethloff et al., 2002). Below, the Root MeanSquare Error $(\mathrm{mm})$ between observations and modelled precipitation. In bold are 717 modelled results closest to observed DMI data.

\begin{tabular}{lcccccc}
\hline \hline \multicolumn{1}{c}{ Station name } & $\begin{array}{c}\text { Station } \\
\text { number }\end{array}$ & DMI & $\begin{array}{c}\text { ERA40 } \\
\left(1^{\circ} \times 1^{\circ}\right)\end{array}$ & $\begin{array}{c}\text { MAR } \\
(25 \mathrm{~km} \times 25 \mathrm{~km})\end{array}$ & $\begin{array}{c}\text { B01 } \\
(50 \mathrm{~km} \times 50 \mathrm{~km})\end{array}$ & $\begin{array}{c}\text { HIRHAM4 } \\
\left(0.5^{\circ} \times 0.5^{\circ}\right)\end{array}$ \\
\hline Pituffik & 4202 & 46.4 & 323.6 & 273.8 & 352.0 & $\mathbf{1 9 2}$ \\
Ilulissat & 4216 & & 433.3 & 364.9 & 780.9 & 432 \\
Aasiaat & 4220 & 361.7 & 400.9 & $\mathbf{2 8 6 . 4}$ & 420.6 & 416 \\
Sismiut & 4230 & 358.1 & 606.7 & 566.9 & $\mathbf{3 6 1 . 9}$ & 344 \\
Kangerlussuaq & 4231 & 152.6 & 467.2 & $\mathbf{3 8 5 . 1}$ & 452.9 & 412 \\
Nuuk & 4250 & 690.2 & 904.6 & 729.1 & $\mathbf{6 7 9 . 5}$ & 936 \\
Paamiut & 4260 & 934.0 & 1089.0 & $\mathbf{8 1 1 . 8}$ & 1094.5 & 1435 \\
Narsarsuaq Lufthavn & 4270 & 794.6 & 1165.0 & $\mathbf{9 4 4 . 4}$ & 1059.2 & 1140 \\
Qaqortoq & 4272 & 998.5 & 1291.1 & $\mathbf{9 0 9 . 8}$ & 1093.4 & 1652 \\
Station Nord & 4312 & 321.5 & $\mathbf{3 5 0 . 6}$ & 474.9 & 233.6 & 800 \\
Danmarkshavn & 4320 & 308.9 & 427.9 & 378.4 & $\mathbf{3 7 3 . 8}$ & 612 \\
Tasiilaq & 4360 & 906.3 & 1186.2 & $\mathbf{1 0 0 8 . 2}$ & 1477.0 & 1596 \\
\hline & & RMSE: & 238.42 & $\mathbf{1 4 7 . 8 7}$ & 239.24 & 398.4 \\
\hline
\end{tabular}


720 Table 2. The Root Mean-Square Error (in percentage of the Greenland ice sheet area) between melt extent simulated by MAR and derived from SSM/I remote sensing observations (Abdalati and Steffen, 1997) in 1990 and 1991. Five different LWC thresholds $(0.5 \%, 0.75 \%, 1 \%, 1.25 \%, 1.5 \%)$ are used to detect melt in MAR snow pack. In $3^{\text {rd }}$ and $4^{\text {th }}$ column called "with rain correction", all the grid points with MAR daily liquid precipitation greater than $1 \mathrm{~mm} /$ day have been not considered in the computation.

726 This table should be examined in conjunction with Figures 3 and 4.

\begin{tabular}{ccccc}
\hline \hline \multirow{2}{*}{ RMSE } & \multicolumn{2}{c}{ Without corrections } & \multicolumn{2}{c}{ With rain corrections } \\
\cline { 2 - 5 } & $\mathbf{1 9 9 0}$ & $\mathbf{1 9 9 1}$ & $\mathbf{1 9 9 0}$ & $\mathbf{1 9 9 1}$ \\
\hline MAR - LWC 0.50 & & & & \\
\% & 5.08 & 5.32 & 4.10 & 4.70 \\
MAR - LWC 0.75 & & & & 3.83 \\
$\begin{array}{c}\text { \% } \\
\text { MAR - LWC 1.00 }\end{array}$ & 3.85 & 4.36 & 2.94 & \\
$\begin{array}{c}\text { \% } \\
\text { MAR - LWC 1.25 }\end{array}$ & 3.10 & 3.92 & & 3.54 \\
$\begin{array}{c}\text { \% } \\
\text { MAR - LWC 1.50 }\end{array}$ & 2.77 & 3.76 & & \\
\% & 2.80 & 3.86 & 2.34 & 3.56 \\
\hline
\end{tabular}




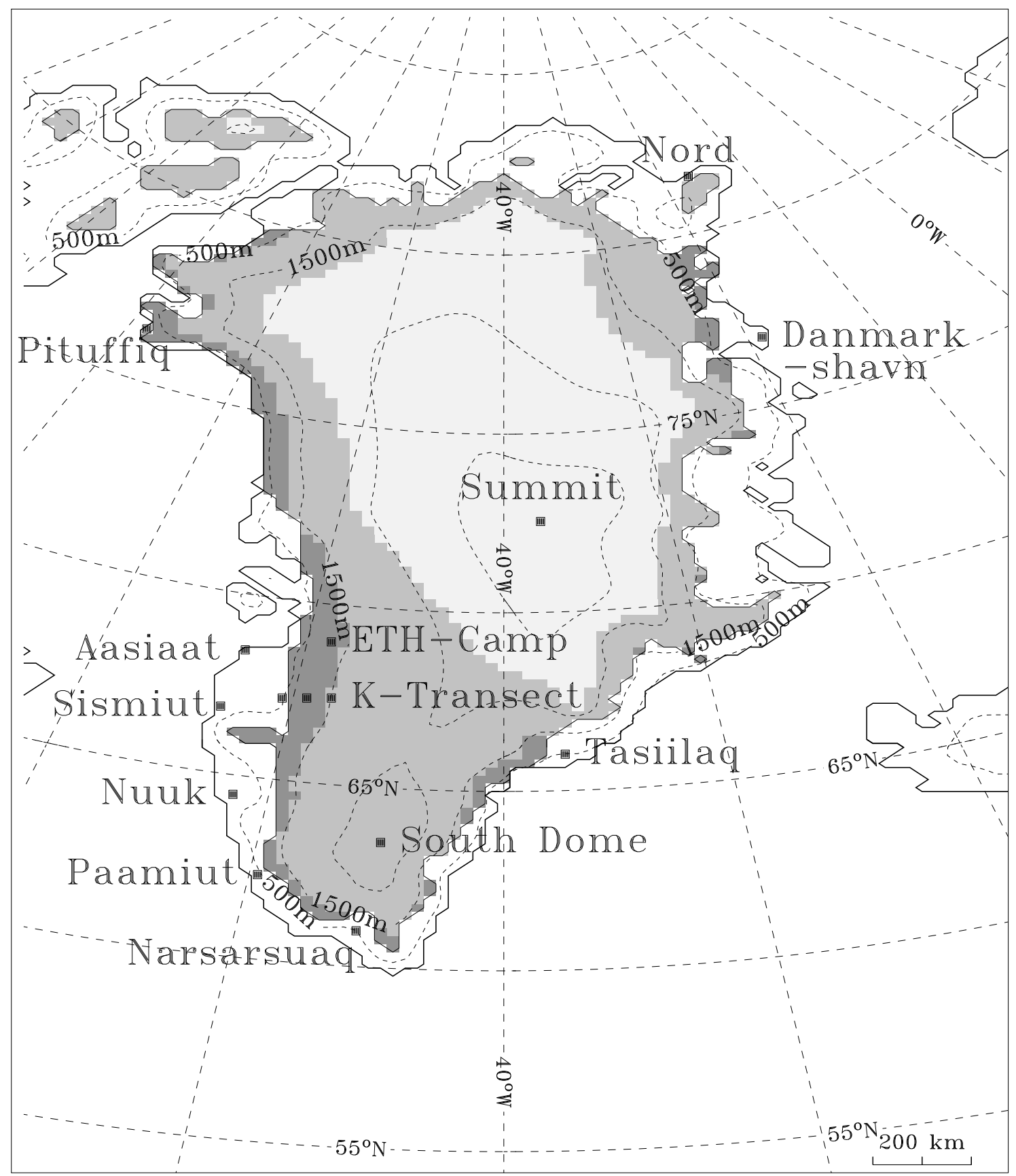

Figure 1. Map of the domain of the simulation showing the MAR mass balance zones distribution used to initialize the snow model according to Lefebre et al. (2004) and locations quoted in the text. From dark grey to light grey on the ice sheet: ice sheet ablation zone, percolation zone and dry snow zone. 

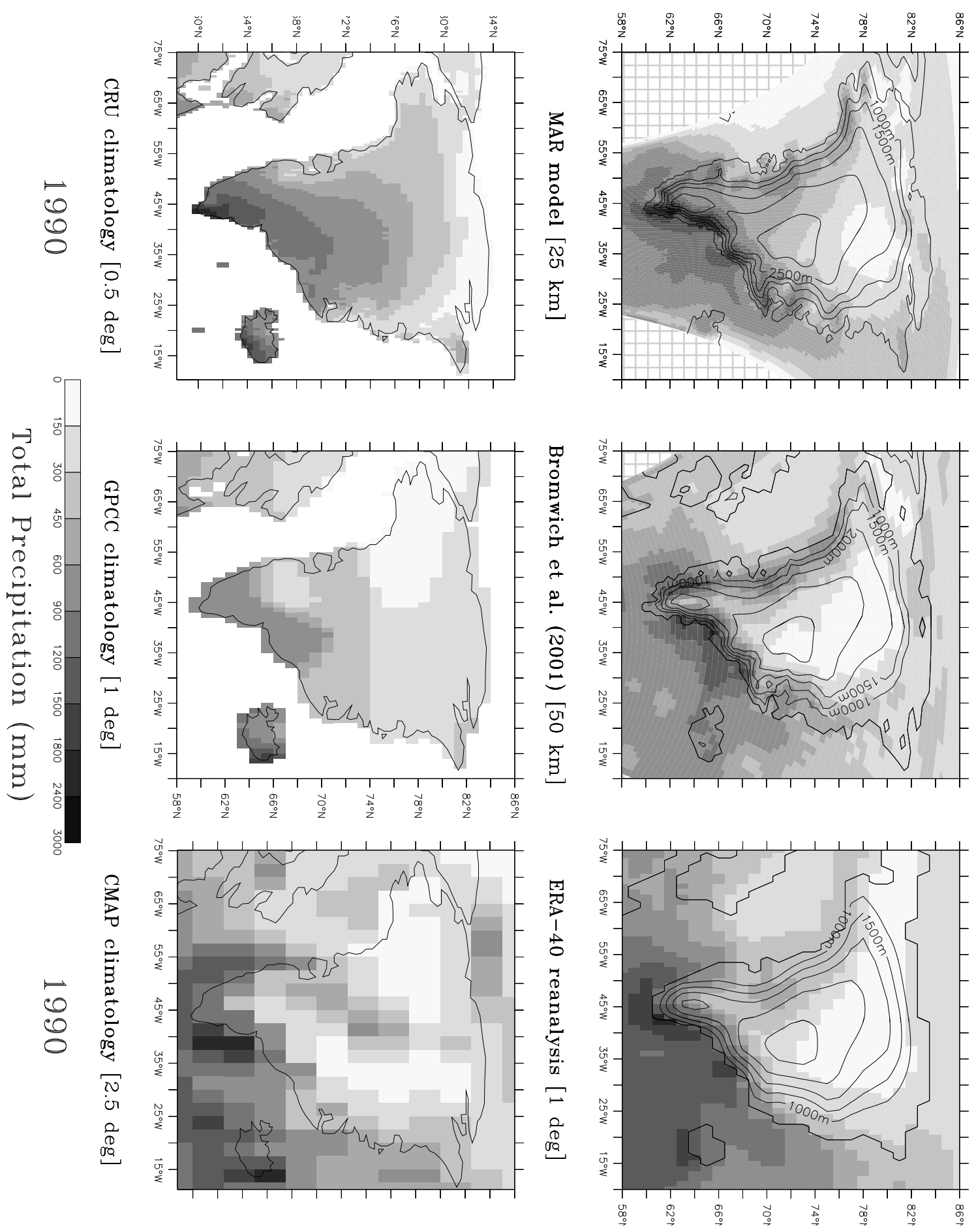

735 Figure 2. Cumulated precipitation (mm) from January 1990 to December 1990, a) simulated by MAR, b) modelled by Bromwich et al. (2001), c) from the ERA-40 reanalysis, d) from monthly 1990 CRU climatology (New et al., 2000), e) from monthly

7381990 GPCC climatology (see http://www.dwd.de/en/FundE/Klima/KLIS/int/GPCC/) and f) from monthly 1990 CMAP climatology (Xie and Arkin, 1997). The resolution is indicated in brackets. The MAR results are shown on a latitude-longitude grid for a better comparison. 

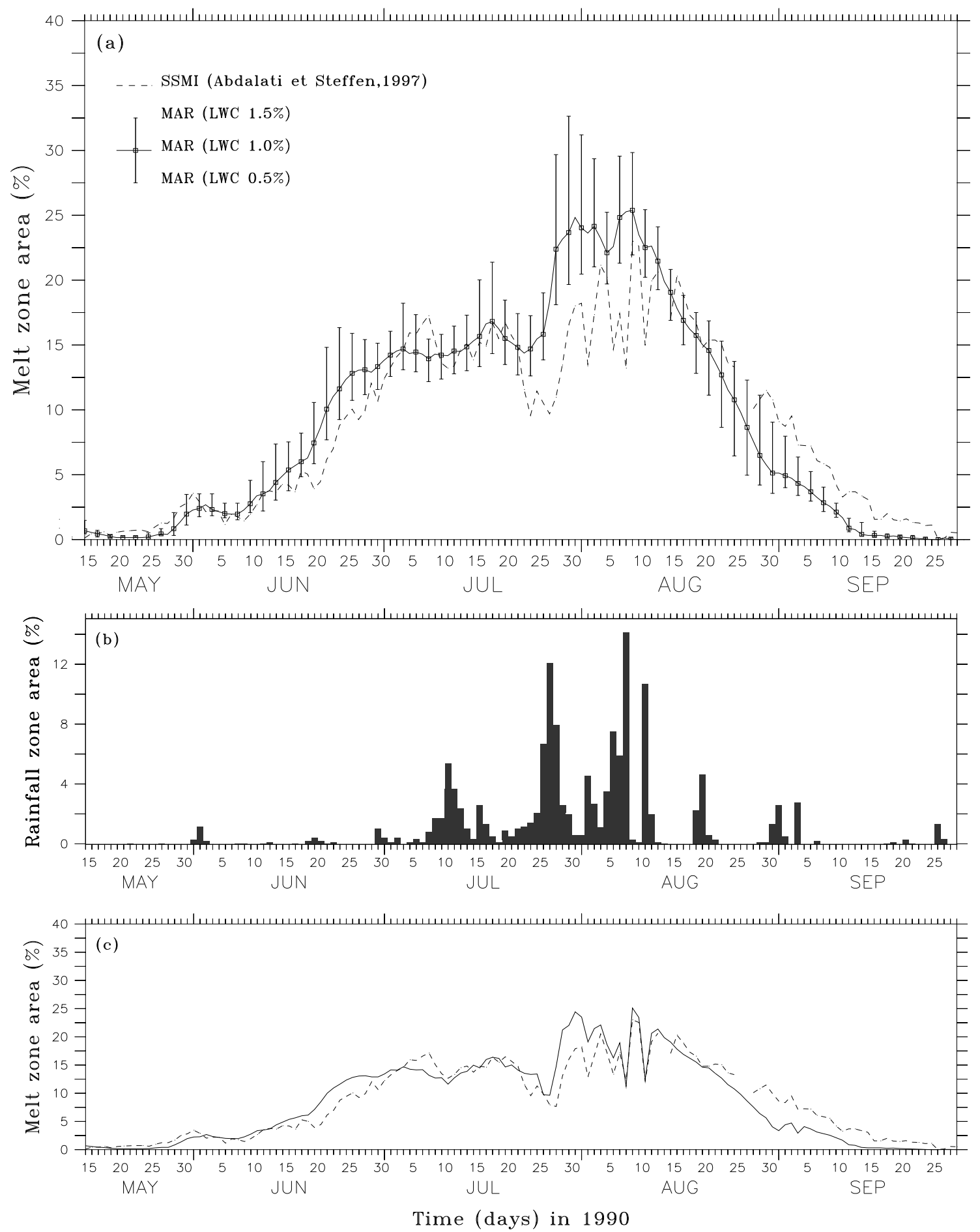

Figure 3. a) Comparison between MAR simulation (solid line) and SSM/I satellite derived observations (Abdalati and Steffen, 1997) (dashed line) of daily average melt extent zone in 1990. Melt is expressed in percentage of the Greenland ice sheet area that lies in the intersection of both MAR and SSM/I grids. Three different LWC thresholds represented by the error bar $(0.5 \%, 1 \%, 1.5 \%)$ are used to detect melt in the MAR snow pack. b) Percentage of Greenland ice sheet area where MAR simulates daily rainfalls greater than $1 \mathrm{~mm} /$ day. c) The same as a), but where all the grid points with MAR daily

750 liquid precipitation greater than $1 \mathrm{~mm}$ /day have been removed in average computation of both MAR and SMM/I fields melt extent. 

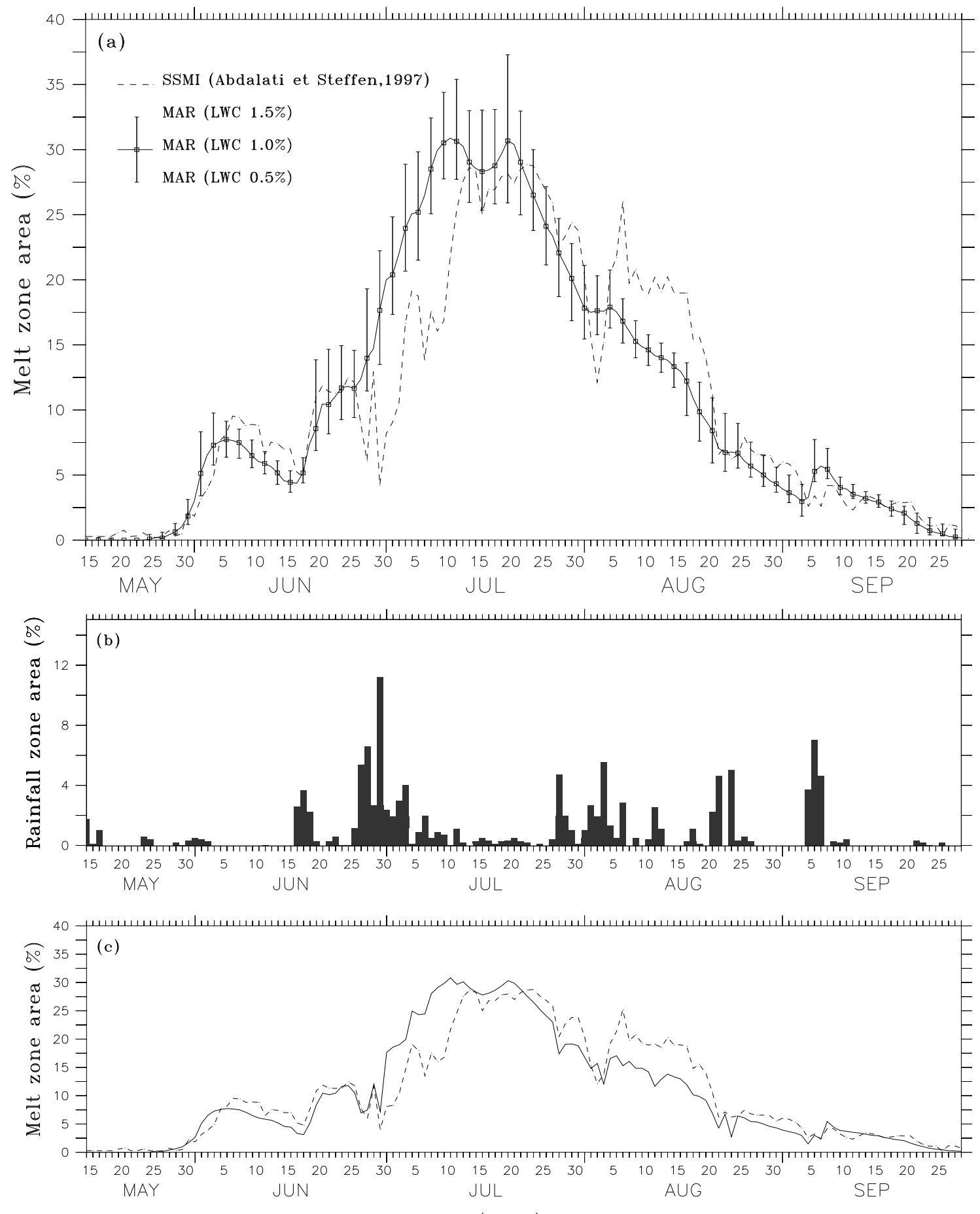

Time (days) in 1991

Figure 4. The same as Figure 3 for 1991. 


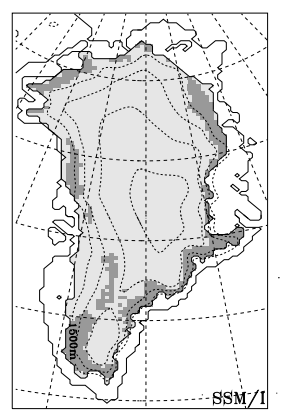

a) 6 August 1990

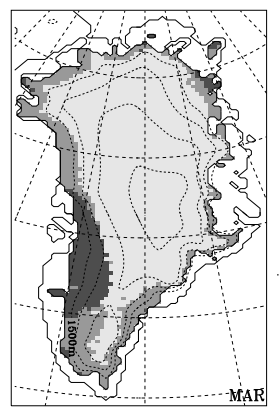

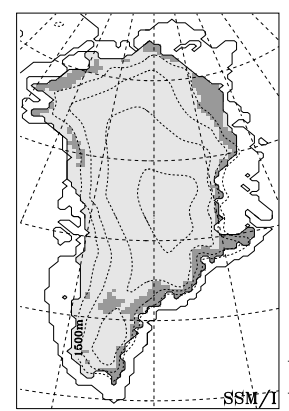

b) 7 August 1990

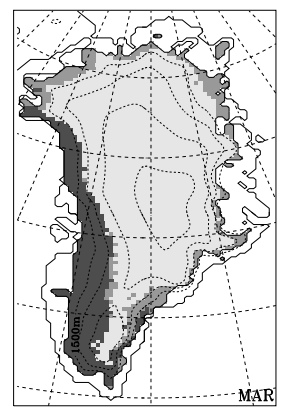

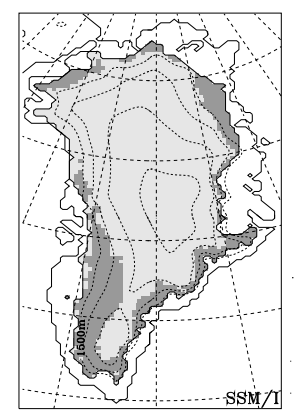

c) 8 August 1990

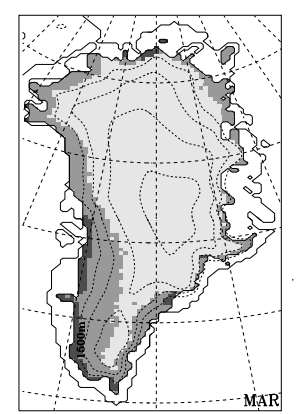

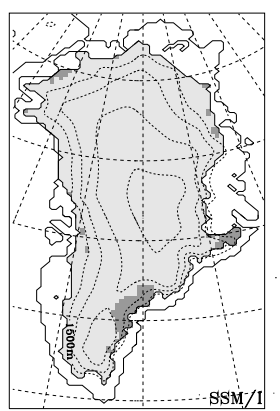

d) 29 June 1991

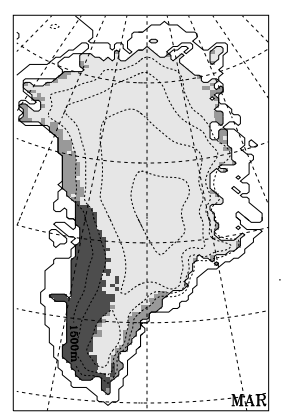

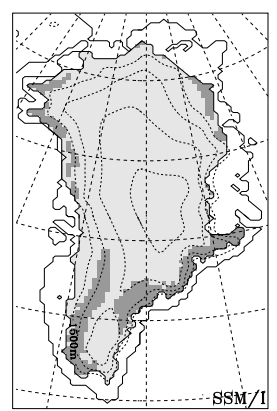

e) 3 August 1991

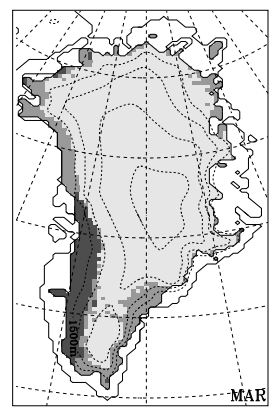

756 Figure 5. Melt extent (in dark grey) derived from SMM/I satellite observation (Abdalati and Steffen, 1997) (top row) and simulated by MAR (bottom row) for different dates. The dark gray zones in MAR fields represent melt zones where MAR simulates daily liquid precipitation higher than $1 \mathrm{~mm} /$ day. The ice sheet extent is drawn in light grey. 

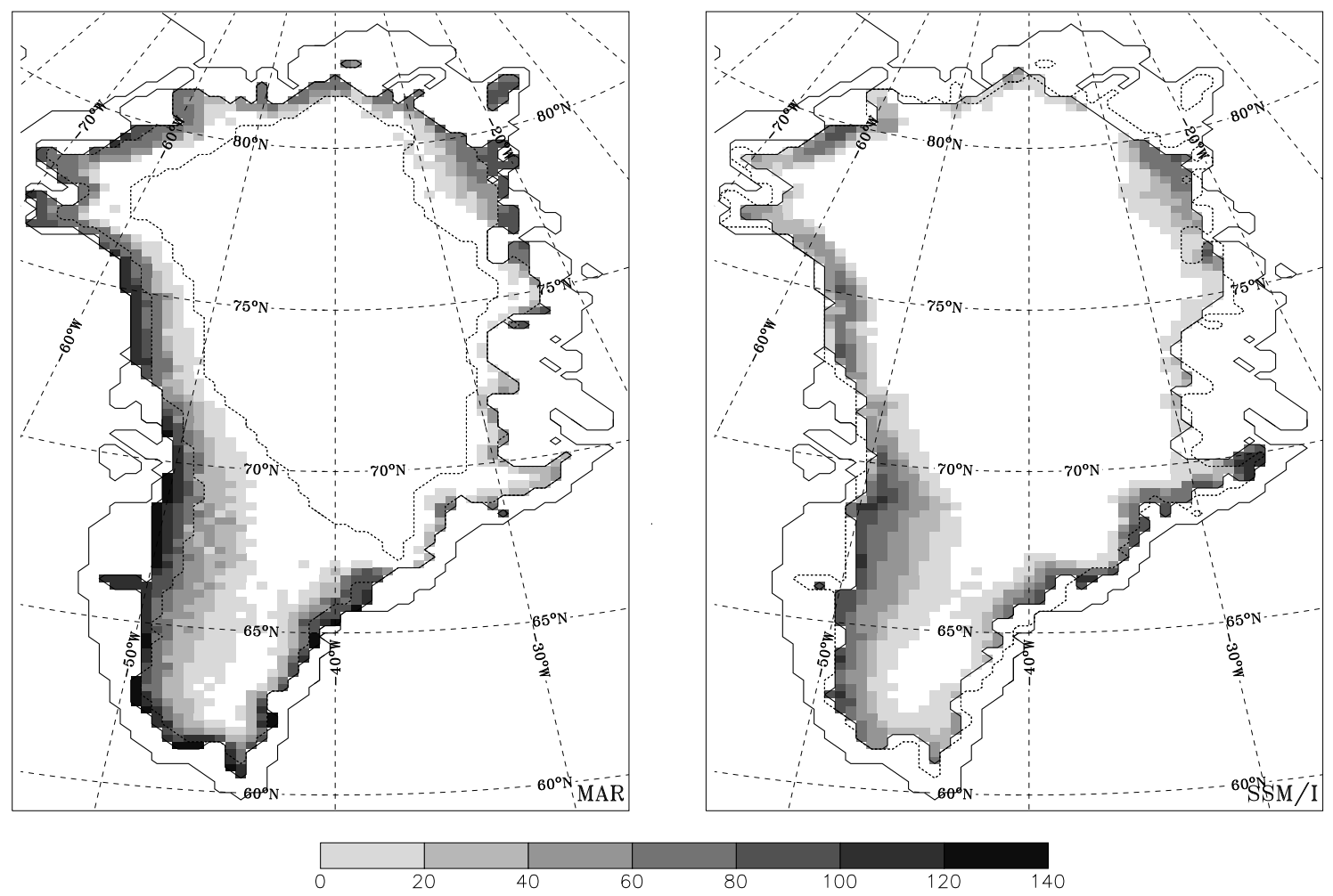

Total number of melt days in 1990

Figure 6. Total number of ablation days from May 1990 to September 1990 simulated by MAR (left) and from Abdalati and Steffen (1997) (right). The dotted lines represent the MAR mass balance zone boundaries in the MAR figure (left) and the MAR ice sheet extension in the SSM/I figure (right). 

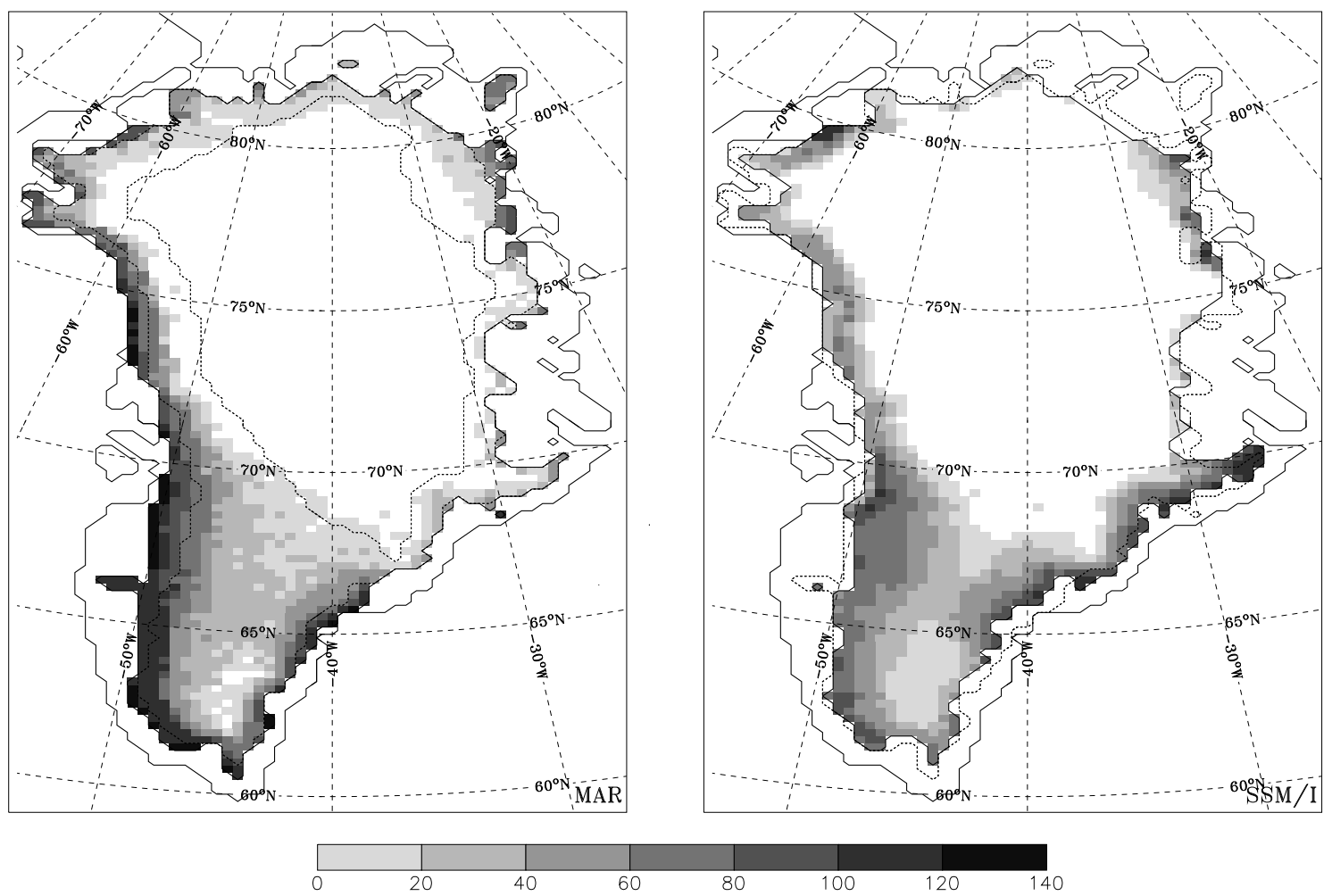

Total number of melt days in 1991

Figure 7. The same as Figure 6 for 1991. 

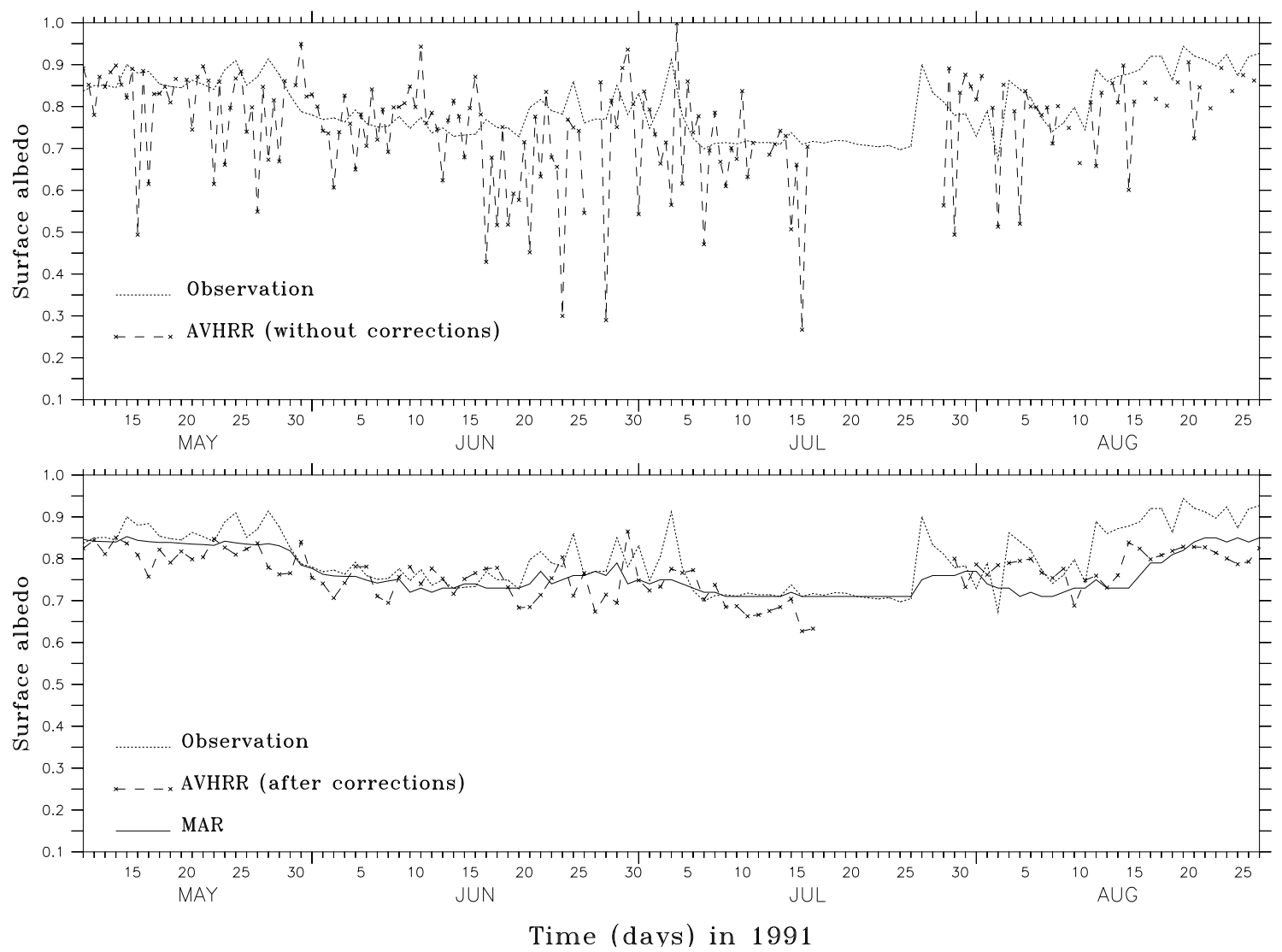

Figure 8. Top: Observed (solid) and AVHRR (dotted) surface albedo at ETH-Camp in 1991 (Ohmura et al., 1992); no corrections have been applied to AVHRR product (Fowler et al., 2000). Below: The surface albedo at ETH-Camp simulated by MAR (dashed), observed (solid) and derived from AVHRR data (dotted) after interpolation on the MAR grid, removal of cloud contaminated pixels and corrections for unrealistic values (see section 3.2.2). 

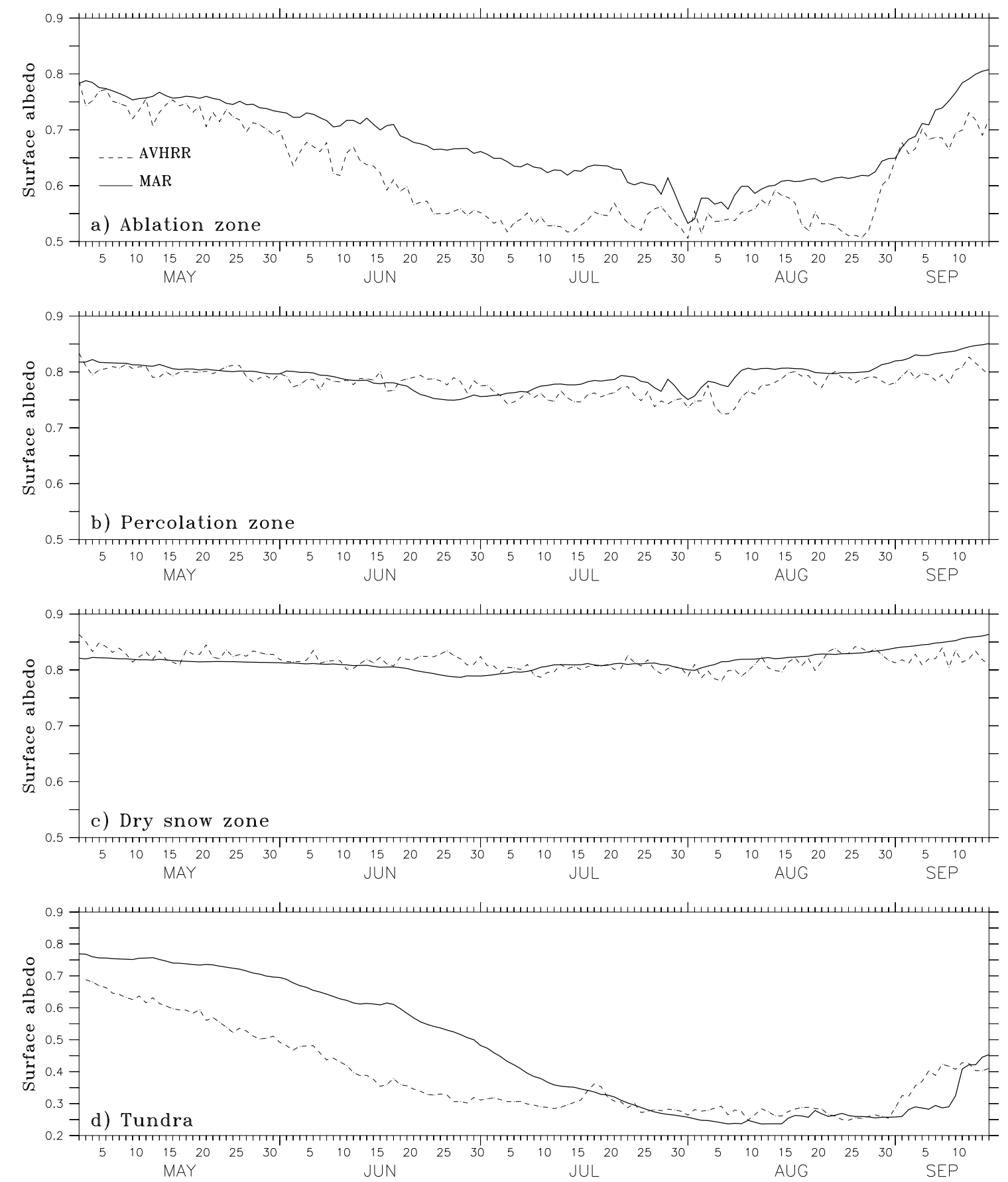

Time (days) in 1990

777 Figure 9. Time evolution in 1990 of the surface albedo averaged a) on the ablation zone, b), on the percolation zone, c) on the dry snow zone, and d) on the tundra simulated by MAR (solid) and derived from APP products (Fowler et al., 2000) (dashed). See Figure 1 for the definition of the zones. 

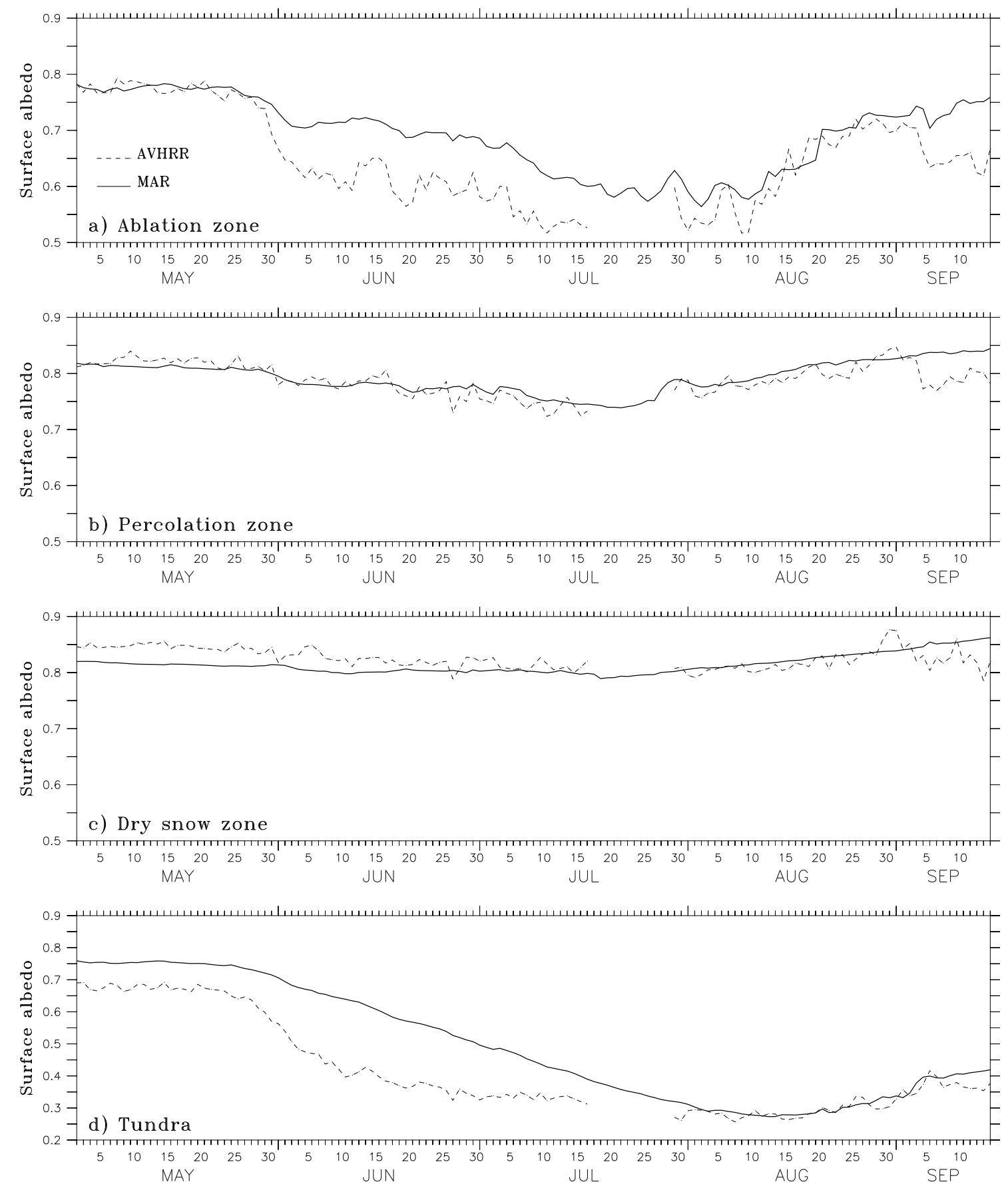

Time (days) in 1991

Figure 10. The same as Figure 9 but for 1991. 

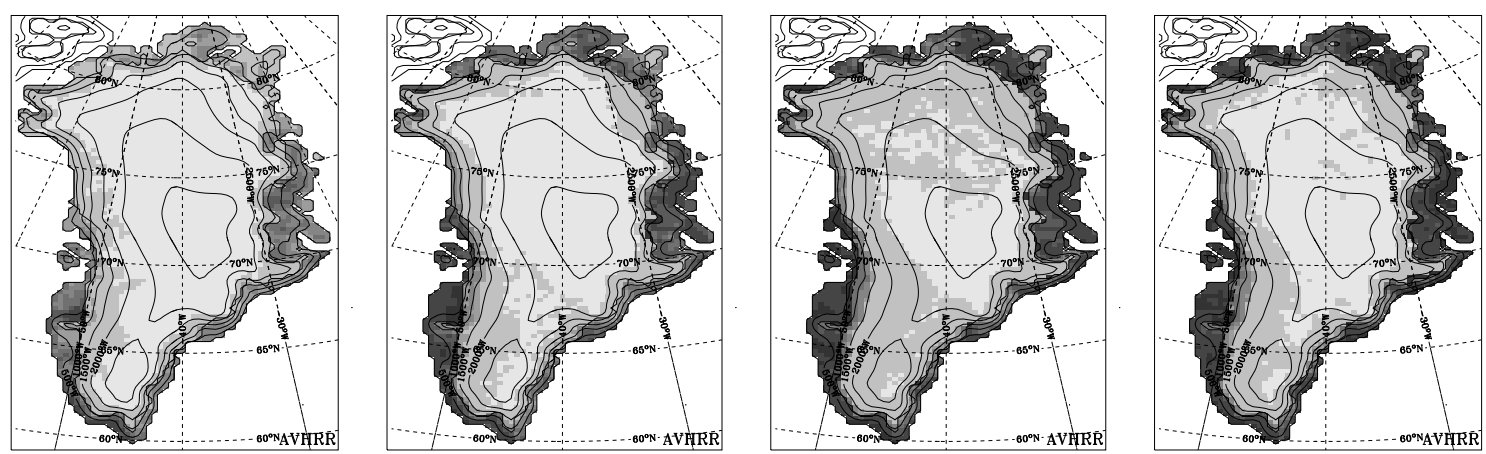

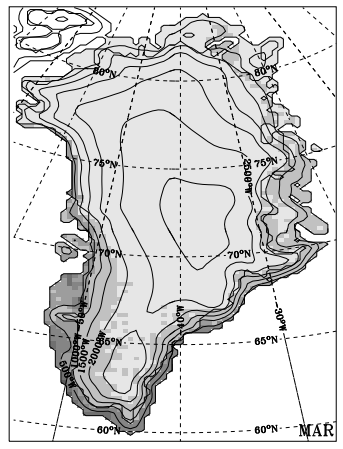

a) May 1990

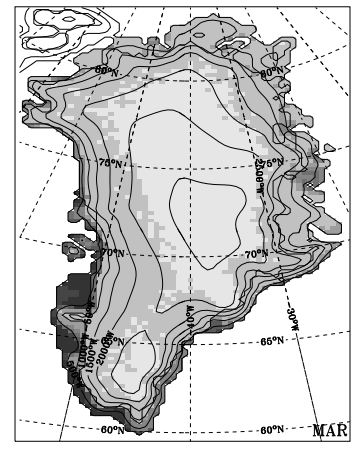

b) June 1990

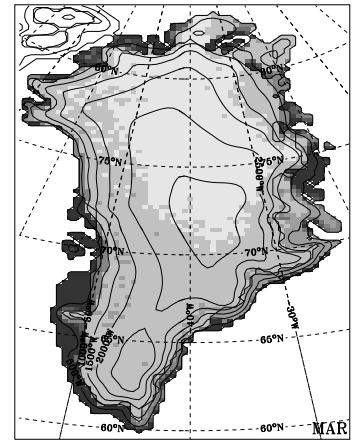

c) July 1990

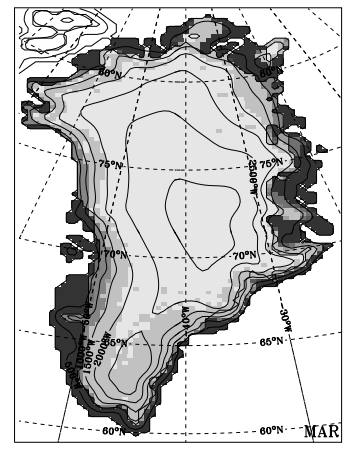

d) August 1990

Figure 11. Monthly mean surface albedo for May, June, July and August 1990, from 786 AVHRR remote sensing observations (top) and simulated by MAR (below). AVHRR values correspond to an average of available pixels after application of the cloud mask. 

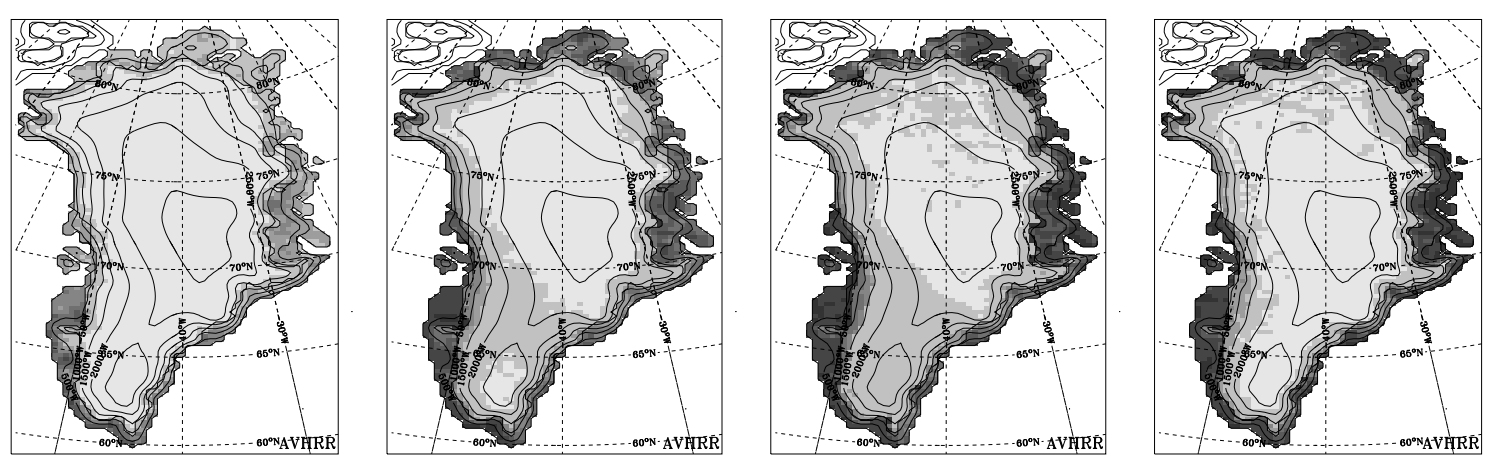

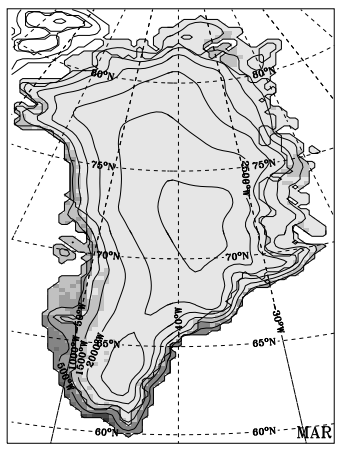

a) May 1991

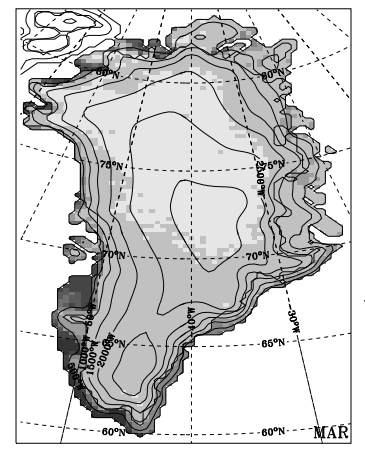

b) June 1991

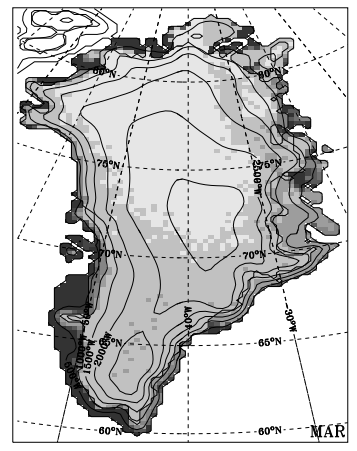

c) July 1991

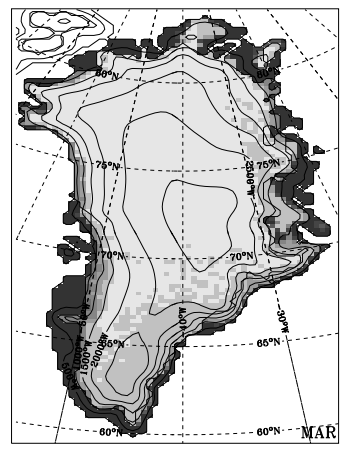

d) August 1991

Figure 12. The same as Figure 11 but for 1991. 